\title{
Servicios de interés general y principio de competencia: del Tratado CEE de 1957 al Tratado de Lisboa de la Unión Europea de 2007
}

\author{
Casimiro López García \\ Interventor-Tesorero de Administración Local
}

Sumario: I. LOS SERVICIOS PÚBLICOS EN EL TRATADO CEE DE 1957. 1. Ausencia de un concepto comunitario de servicio público. 2. La iniciativa pública económica en los Tratados de la Comunidad Económica Europea.-II. LA POLÍTICA COMUNITARIA DE PRIVATIZACIÓN. 1. El proceso de liberalización y privatización de los servicios de redes. - III. EL CONCEPTO DE SERVICIO UNIVERSAL. - IV. EL CONCEPTO DE SERVICIO DE INTERÉS GENERAL.-V. LIBRO VERDE DE LA COMISIÓN, DE 21 DE MAYO DE 2003, SOBRE LOS SERVICIOS DE INTERÉS GENERAL. 1. Alcance la acción comunitaria. 2. Necesidad de establecer un concepto de Derecho comunitario del servicio de interés general. 3 . Alcance de la discrecionalidad de las autoridades nacionales. 4. Financiación de los servicios de interés económico general. 5. Resolución del Parlamento Europeo, de 13 de enero de 2004, relativa al Libro Verde sobre los servicios de interés general.-VI. COMUNICACIÓN DE LA COMISIÓN AL PARLAMENTO EUROPEO, AL CONSEJO, AL COMITÉ ECONÓMICO Y SOCIAL EUROPEO Y AL COMITÉ DE LAS REGIONES, DE 12 DE MAYO DE 2004 «IBRO BLANCO SOBRE LOS SERVICIOS DE INTERÉS GENERAL». 1. Responsabilidad compartida. 2. Objetivo estratégico. 3. Principios rectores de la política de la Comisión. - VII. COMUNICACIÓN DE LA COMISIÓN, DE 26 DE ABRIL DE 2006, «APLICACIÓN DEL PROGRAMA COMUNITARIO DE LISBOA. SERVICIOS SOCIALES DE INTERÉS GENERAL EN LA UNIÓN EUROPEA».-VIII. DIRECTIVA 2006/111/CE DE LA COMISIÓN, DE 16-11-2006. 1. Alcance de las medidas de información y control. 2. Concepto de empresa pública. 3. Modalidades y tipos de ayudas. 4. Ámbito de aplicación y exclusiones. - IX. TRATADO DE LISBOA DE 13 DE DICIEMBRE DE 2007. 1. Codificación del concepto de servicios de interés económico general. 2. Protocolo sobre los servicios de interés general. 3. Principio de subsidiariedad y cláusula de preferencia local. 4. Tratado de Funcionamiento. 5. Transportes y ayudas públicas. 6. Declaraciones relativas a las disposiciones de los tratados.

\section{LOS SERVICIOS PÚBLICOS EN EL TRATADO CEE DE 1957}

\section{Ausencia de un concepto comunitario de servicio público}

El Tratado de la Comunidad Económica Europea, de 25 de marzo de 1957, sienta las bases para superar definitivamente la sucesión de guerras por el dominio continental, mediante la creación de un verdadero mercado común entre grandes países de la Europa occidental, y abre un proceso de colaboración entre los grandes Estados que permite promover nuevas fórmulas de integra- 
ción política. Los Tratados ${ }^{1}$ establecen un proceso dinámico que se inicia con una política agraria común y por la libre circulación de mercancías en un mercado presidido por las reglas de la competencia y la prohibición de la discriminación. La consecución de estos primeros objetivos requiere la progresiva supresión de los aranceles interestatales y establecimiento de un arancel común, y la supresión de los monopolios fiscales sobre tabacos y carburantes, fundamentalmente. Los servicios públicos, a pesar de su manifiesta importancia política y económica y de su evidente configuración como monopolio público opuesto a las reglas de la competencia, sólo tienen una mención específica en el art. 77 del TCCE, en materia de transportes. Para identificar esta realidad, el TCCE establece el concepto de servicio de interés económico general, con la intención de superar la degradación total y absoluta de un concepto del que hay tantas definiciones como autores (ALESSI), que ha terminado por convertirse en «una expresión equívoca, con la que se arriesga a engendrar las peores confusiones» (COUZINET), sin otro valor que el de una simple etiqueta (WALINE); y la existencia de distintas tradiciones jurídicas estatales para fundamentar las prestaciones de servicio público ${ }^{2}$.

La definición de las necesidades y objetivos públicos a organizar y prestar por los poderes públicos al margen del mercado, y las modulaciones al principio de la libre competencia que tales prestaciones pudieran justificar estaban por concretar, pero quedaban anunciadas en el artículo 90.2 del Tratado de la Comunidad Europea (86.2, versión Maastricht), al afirmar que «las empresas encargadas de la gestión de servicios de interés económico general o que tengan el carácter de monopolio fiscal quedarán sometidas a las normas del presente Tratado, en especial a las normas sobre competencia, en la medida en que la aplicación de dichas normas no impida, de hecho o de derecho, el cumplimiento de la misión específica a ellas confiada». El Derecho comunitario, para superar las diferencias entre los Estados de corte francés y sistema de la «publicatio» formal de actividades de servicio público, y de los que siguen la vía de la regulación de los elementos precisos para asegurar la prestación regular y continua de las obligaciones de servicio público, adopta sus propias formas y definiciones: la expresión «misión específica» y la de servicios de interés económico general engloba las distintas acepciones del concepto ${ }^{3}$ de servicio

\footnotetext{
1 Hasta el Tratado de Lisboa de diciembre de 2007 se ha mantenido la estructura original del Tratado del Carbón y del Acero de 1951 (CECA); del Tratado de la energía Atómica (EURATOM) y del Tratado político y comercial (CCE)

2 Tomás Ramón FERnÁNDEZ RodRíGUEZ. «Del Servicio Público a la liberalización, desde 1950 hasta hoy» $R A P$, op. cit. 2 esta ausencia porque el concepto no es general, sino privativo de algunos Estados miembros, que han canalizado a lo largo de su historia preferentemente (aunque no exclusivamente, como ya hemos visto) por la vía de la publicatio formal de algunas actividades su respuesta a un problema que sí es general y común a todos ellos, cubrir la distancia existente entre el espacio vital dominado y el espacio vital efectivo, y que los demás han salvado por la vía alternativa de la regulación de las actividades en cuestión.

3 Villar Ezcurra. Derecho Administrativo Especial. Administración Pública y actividad de los particulares, Ed. Civitas, Madrid, 1999).
} 
SERVICIOS DE INTERÉS GENERAL Y PRINCIPIO DE COMPETENCIA: DEL TRATADO CEE...

público, para establecer un concepto propio, cuya fuerza expansiva le permiten afianzarse sobre el Derecho de los Estados.

La tensión entre los principios de libre mercado y los monopolios nacionales de servicio público se agudiza desde la entrada en vigor del Acta Única de 1986, que configuró un verdadero mercado único; añadiendo a la libre circulación de mercancías, la de movimientos de capital y la libre circulación de los trabajadores. Lo que unido al auge del movimiento privatizador del sector público industrial, generará un debate sobre la defunción del Estado del bienestar que se mantiene hasta la fecha en todos los Estados, y que ha tenido y tiene especial virulencia en Francia ${ }^{4}$, como lo muestra su rechazo al proyecto de Constitución Europea en el referendum, de 29 de mayo de 2005. La discusión sobre el ámbito, forma y contenido de los servicios públicos acompaña a los Tratados desde sus orígenes, y está recíprocamente relacionada con la idea y la función del mercado ${ }^{5}$, y con la existencia de necesidades generales que no se sufragan ni prestan por el mercado y tampoco pueden ser atendidas individualmente.

No deben confundirse las misiones y finalidades de servicio público vigentes en las distintas constituciones de los Estados con su concreta configuración ${ }^{6}$, que a su vez nos recuerda la larga discusión doctrinal entre los partidarios de un concepto amplio de servicio público (DUGUIT), que llega a identificarse con la iniciativa del poder, y los partidarios de un concepto estricto o técnico (GARRIDO FALLA) que se identifica con los entes instrumentales y sus medios de prestación?

En Derecho comunitario, la distinción entre servicios de naturaleza económica y servicios de naturaleza no económica es la única que cuenta. Los principios de Derecho comunitario: libertad de circulación personal, no discriminación, libertad de prestación de servicios, el derecho de libre establecimiento, y las normas en materia de competencia y prohibición de ayudas estatales tienen alcance general y se aplicarán de inmediato a todo tipo de actividades económicas públicas o privadas. Desde el primer día entran en contradicción con las empresas públicas que tienen que someterse al mercado, y con los monopo-

\footnotetext{
4 Concepto de servicio público constitucional del Consejo de Estado francés 25-26, de junio 1986.

5 Santiago MuÑoz MaChado. Servicio público y mercado. I. Los fundamentos, Ed. Civitas, Madrid, 1998

6 J. L. VILlar Palasi. «La actividad industrial el Estado en el Derecho Administrativo», op. cit. num.5, ««las técnicas jurídicas actúan a modo de títeres en la continua farsa histórica de creación del Poder. Surgen para dar forma a una finalidad concreta, pero... el momento finalista de todo concepto jurídico se derrite rápido como la cera».

7 T. Ramón FERNÁNDEZ RODRÍGUEZ. Op cit, n. ${ }^{\circ} 2$ «El servicio público ha sido y es una técnica más, una técnica que pretende dar respuesta a una idea política que también denominamos, por cierto, con esa misma expresión. En otros lugares, ahora bien próximos, a esa misma idea se la denomina de forma diferente y se la da respuesta con una técnica también distinta: las publie utilites, por ejemplo, del Derecho anglosajón».
} 
lios fiscales, que tienen que suprimirse. Sólo las actividades de interés económico general escaparán en el primer momento a sus efectos ${ }^{8}$.

\section{La iniciativa pública económica en los Tratados de la Comunidad Económica Europea}

Las sucesivas versiones de los Tratados CEE y EURATON de 1957, y CECA de 1951, incluyen pocas referencias a la iniciativa económica pública y a los servicios de interés económico general:

Empresas públicas: apartado 1 del artículo 86 y 295; no existe reserva ni trato especial, les resultan de aplicación todas las normas comunitarias sobre prohibición de toda discriminación por razón de nacionalidad y las reglas de competencia sin excepción. La evidente vinculación entre autoridades públicas y empresas estatales, y la existencia de todo tipo de ayudas, obligaron a la Comisión a establecer una vigilancia especial y a la aprobación de la Directiva $80 / 723$, de 25 de junio, sobre transparencia de las relaciones financieras entre los Estados miembros y sus empresas públicas 9 .

Derechos especiales o exclusivos y supresión monopolios comerciales: artículo 31 y apartados 1 y 2 del artículo 86 . El artículo 31 prohibía la discriminación entre los nacionales de los Estados miembros por los monopolios nacionales de carácter comercial ${ }^{10}$.

Servicios públicos: artículos 16, 30, 46, 73 y apartado 2 del artículo 86 .

El Tribunal de Justicia Comunitario (TJCE) no utiliza el concepto de servicio público, en su lugar, se refiere a las actividades económicas de interés general creadas por las autoridades públicas o a las que funcionan bajo su responsabilidad, aunque la gestión esté cedida a un operador (público o privado) exterior a la administración. El concepto se aplica también a las actividades económicas denominadas de prestación en red: distribución de electricidad, gas y agua, correos y telecomunicaciones. El Tratado de Roma los denominó «servicios de interés económico general», y autorizó su excepcionalidad y la efectiva exen-

\footnotetext{
8 Por el contrario, la libertad de circulación personal y el principio de no discriminación tienen un alcance general y resultan de obligada aplicación en todos los ámbitos, especialmente, en los denominados servicios de interés general no económicos, que se identifican con los denominados derechos sociales y asistenciales: acceso a la cultura y a la educación, a la sanidad y a los servicios sociales, de tal manera que se oponen a toda regla fiscal o administrativa que directa o indirectamente beneficie a los nacionales de los Estados sobre el resto de ciudadanos de la Unión.

9 El suministro regular de información y las reclamaciones para la devolución de ayudas contrarias a los Tratados se imponen definitivamente con la modificación de la Directiva en 1993.

10 Los seis primeros Estados miembros procedieron a las modificaciones necesarias antes de 1970. Tras cada ampliación, los nuevos Estados miembros han llevado a cabo estas mismas modificaciones. En España supuso la desaparición del monopolio de petróleos y tabacos.
} 
ción de las normas de libre circulación y de competencia, fundamentalmente, por resultar necesario para el cumplimiento de los fines y misiones que tienen encomendados (artículo 86.2); también por razones de seguridad y salud pública (artículos 30 y 46), y por otras consideraciones de interés general que justifican la exención de las normas de competencia del artículo 87.3 y del 82.3.

El Acta Única y el Tratado de Maastricht añadieron la promoción de la cohesión económica y social, la protección de los consumidores y la necesidad de establecer redes transeuropeas.

Las disposiciones aplicables al sector de los transportes (artículo 73) admiten las ayudas públicas destinadas a compensar las «obligaciones inherentes a la noción de servicio público», único caso en que esta expresión se utiliza en el Tratado.

El Derecho comunitario, para superar las dificultades de un concepto que tiene un significado jurídico diverso según las distintas culturas jurídicas de los Estados miembros y una evolución propia en cada Estado, se ha visto obligado a establecer el de servicios de interés general, que tiene su propio desarrollo empujado y auspiciado por la doctrina del $\mathrm{TJCE}^{11}$, para identificar aquellos servicios de interés general excluidos en todo o en parte de la disciplina de mercado, a los que las autoridades públicas han calificado de interés general, al objeto de someterlos a obligaciones específicas de servicio público. Tradicionalmente se han prestado por las autoridades públicas; sin embargo, por aplicación del Pacto de Estabilidad y Crecimiento, la participación privada es creciente ${ }^{12}$.

\section{LA POLÍTICA COMUNITARIA DE PRIVATIZACIÓN}

La aplicación del principio de neutralidad cerraba el paso a las iniciativas de regulación de las empresas públicas impuesta por el Tratado (artículo 295 Ams-

\footnotetext{
11 Para solventar los problemas de convivencia entre los sistemas judiciales comunitarios y los nacionales, que sin órgano especial deben aplicar el Derecho Comunitario, los Tratados constitutivos de la Unión Europea establecen un procedimiento que permite plantear ante el Tribunal de la Unión, hoy ante el Tribunal Superior de Justicia de la Unión, al haberse establecido con otras competencias y cometidos el Juzgado de Primera Instancia, las dudas interpretativas y de validez del derecho comunitario aplicable por el Juez nacional. De tal manera que se establece un cauce de participación de los jueces nacionales en la interpretación y en la declaración de validez del Derecho Comunitario.

La regulación legal de la Cuestión Prejudicial se figuraba en el artículo 177 TCEE, que establece: «El Tribunal de Justicia será competente para pronunciarse con carácter prejudicial: sobre la interpretación del presente Tratado; sobre la validez e interpretación de los actos adoptados por las instituciones de la Comunidad y por el Banco Central Europeo; Sobre la interpretación de los estatutos de los organismos creados por un acto del Consejo, cuando dichos estatutos así lo prevean.»

12 Libro Verde sobre la colaboración público-privada y el derecho comunitario en materia de contratación pública y concesiones [COM (2004) 327 final - no publicado en el Diario Oficial].
} 
terdam, antiguo 222), sólo la necesidad de establecer un verdadero mercado común modificará la situación. Desde principios de los años 90, la Comisión Europea adoptará una política mucho más beligerante con los derechos exclusivos y especiales, proponiendo políticas concretas para la liberación de los servicios de redes ${ }^{13}$. A pesar de la doctrina del Tribunal de Justicia Comunitario (TJCE) SS Corbeau y Almelo, de 1993 y 1994, que reconocen la excepción prevista por el apartado 2 del artículo 86 (90) para proteger las actividades de servicio público de las normas de liberalización y competencia ${ }^{14}$. La Comisión seguirá adelante con su empeño liberalizador de los monopolios estatales, aprobando las denominadas Directivas de red, (telecomunicaciones, electricidad, gas, ferrocarriles) que suprimen los derechos especiales y exclusivos de las empresas públicas, y privatizan estos sectores que sólo conservarán obligaciones de servicio público impuestas a los operadores dominantes, que pasan a denominarse obligaciones de «servicio universal» de contenido limitado.

Telecomunicaciones: Se liberaliza su prestación, en el marco del concepto de servicio universal, que reconoce el derecho de los usuarios al acceso a partir de un teléfono fijo a las llamadas internacionales y nacionales así como a los servicios de socorro ${ }^{15}$.

Transporte: La liberalización interna de los transportes por carretera no se generaliza hasta 1998. El acceso al mercado internacional se liberalizó el 1 de junio de 1992. En el transporte marítimo la liberalización de los servicios de cabotaje marítimo se realizó en 1993. Pero es en el transporte aéreo donde se han realizado los mayores progresos, a raíz de la terminación del proceso de liberalización del mercado el 1 de julio de 1998, que ha introducido con inusitado éxito las compañías de bajo coste, que han multiplicado los destinos, los vuelos y el número de pasajeros en esta década.

Energía: La apertura de los sectores del gas y la electricidad a la competencia es aún demasiado reciente para que se pueda hacer balance. Sólo a partir del 2000 los Estados miembros se han visto obligados a abrir su demanda interna de electricidad y gas a la competencia europea. A partir de 2007 se inician los movimientos de fusión empresarial entre las grandes compañías antes estatales; no obstante, el proceso no avanzará mientras los Estados no conecten sus redes básicas de distribución y establezcan acuerdos mínimos de producción.

\footnotetext{
13 Santiago MuÑoz MaCHADO. «Servicio Público y Mercado», op. cit. núm. 5.

14 Esto tiene, como es natural, unas consecuencias enormes, que además el Tribunal de Luxemburgo está enriqueciendo con apoyo en técnicas contables, pues exige que las empresas que tengan misiones específicas diferencien contablemente sus actividades, y permite, por tanto, que esas empresas puedan tener ayudas públicas y, en general, una posición en cierta medida privilegiada al realizar una función que escapa de lo que son las reglas del mercado propias de las empresas privadas.

15 La Directiva no cubre ni la telefonía móvil ni el acceso por banda ancha a internet. A raíz de la entrada en el mercado de la televisión comercial en los años 80 (Directiva 90/388/CEE), la liberalización en el sector de la televisión fue confirmada por la Directiva «Televisión sin fronteras».
} 
Servicios postales: El Parlamento Europeo y el Consejo de Ministros de la UE adoptaron una propuesta que modificaba la Directiva 97/67/CE con el fin de liberalizar los servicios postales antes del 2003 para el correo de hasta 100 gramos, y antes del 2006 para el correo de más de 50 gramos.

\section{El proceso de liberalización y privatización de los servicios de redes}

El proceso de liberalización lanzado por la Comisión europea es una prueba de su confianza en el mercado para mejorar la asignación de recursos, facilitar el crecimiento económico, y conseguir un beneficio general vía precios y calidad de la prestación. Para evitar la exclusión de una parte de la población de sus beneficios y fomentar la cohesión social y territorial, se introduce el concepto de servicio universal como punto de equilibrio entre la competencia y las exigencias del interés general. En estos sectores, se supera el concepto tradicional de servicio público en monopolio para establecer una situación de oligopolio material, presidido por la reglamentación e imposición de obligaciones materiales de servicio público, que se denominan «servicio universal» ${ }^{16}$. En materia de servicios económicos en red, la Comisión Europea, a pesar de las reticencias del TJCE ${ }^{17}$, impuso su política liberalizadora, que tras la liberalización ya no forman parte del sector público.

El concepto de interés económico general comunitario se impone así al concepto de interés nacional que figura en el 128.2 Constitución Española (CE); el Estado y el resto de los poderes territoriales ya no podrán establecer reservas a favor del sector público - y menos establecer monopolios- en los denominados servicios económicos de interés general liberalizados (servicios de redes); tampoco podrán establecer reservas o monopolios en todo el entramado de organismos y empresas que ejercen su actividad en todo tipo de servicios económicos que son de evidente interés general. Lo que no significa que tal liberalización con privatización convenga en todo tipo de sectores y servicios económicos públicos, puesto que sería tanto como liquidar toda presencia pública en la prestación de todo tipo de iniciativas económicas de las que depende el futuro de la investigación, la educación, la sanidad o la defensa, y que nunca se prestarán por el sector privado ${ }^{18}$. La definición concreta de las obligaciones de servicio público universal se dejaba a cargo de cada Estado miembro, que den-

\footnotetext{
16 M. ${ }^{\text {a }}$ Y. FERNÁNDEZ GARCÍA, «Las obligaciones económicas de los operadores de los servicios esenciales económicos en red», RAP, págs. 127-140, núm. 163, enero-abril, (CEPC), Madrid, 2004.

17 El TJCEE confirmó su postura de hacer intervenir la excepción a las normas de liberación y competencia contemplada en el apartado 2 del artículo 86 en favor de los servicios públicos: véase en particular sus sentencias de 23 de octubre de 1997 en los asuntos Comisión de las Comunidades Europeas contra España, Francia, Italia y los Países Bajos, a propósito de los derechos exclusivos de importación de electricidad y gas.
}

18 F. Sosa Wagner (Coordinador), Vol. colectivo El Derecho Administrativo en el umbral del S. XXI. Homenaje al Profesor Doctor D. Ramón Martín Mateo, págs. 2459-2573, Valencia, 2000. 
tro de los términos ${ }^{19}$ obligatorios de las Directivas, tiene que definir el interés general y sus exigencias en materia de servicio universal y de otras obligaciones de servicio público, y establecer, en su caso, las compensaciones correspondientes a las empresas que hayan de soportar el coste adicional con cargo a fondos nutridos por las aportaciones de los demás operadores que estén libres de estas cargas $^{20}$.

\section{EL CONCEPTO DE SERVICIO UNIVERSAL}

El concepto de servicio universal nace al socaire de las Directivas liberalizadoras $^{21}$ de los servicios económicos de red (telecomunicaciones, electricidad, servicios postales) y hace referencia a los requisitos mínimos exigibles para que tales servicios se presten a los consumidores con una calidad mínima igual en todo el territorio a un precio asequible, que asegure la regularidad y universalidad de la prestación. Se trata de reconocer a todos los ciudadanos el derecho a acceder a ciertos servicios considerados esenciales y de imponer a las empresas la obligación de prestar un servicio mínimo en las condiciones especificadas, incluida una cobertura territorial completa. También sirve para establecer un proceso contrario al de la privatización, al facilitar la imposición de obligaciones de servicio público a determinadas actividades privadas, que quedan así sometidas al poder público de regulación y dirección por razones de interés general. Lo que supone un nuevo concepto de servicio público o concepto material de servicio público, al incorporar la técnica anglosajona de las utilidades públicas. En palabras de MUÑOZ MACHADO: «El servicio público pierde su carácter orgánico, para pasar a ser una noción material, que se refiere a actividades gestionadas en condiciones jurídicas exorbitantes del derecho común, tanto por las Administraciones públicas como por los particulares» ${ }^{22}$.

19 J. L. LÓPEZ MuÑíZ. «En tono a la nueva regulación de los servicios económicos en red», (a propósito de la nueva Ley de telecomunicaciones y su sistema conceptual)» Vol. col. El Derecho Administrativo en los umbrales del S. XXI, homenaje al P. D. Ramón Martín Mateo (Vol. III Tirant Lo Blanc), Valencia, 2000.

20 En España se aprobaron las leyes del Servicio Postal Universal y de Liberalización de los Servicios Postales, de 13 de julio de 1998; General de las Telecomunicaciones, de 24 de abril de 1998; del Sector Eléctrico, de 27 de noviembre de 1997 que, tras sucesivas modificaciones y adaptaciones, han servido para asentar el concepto y facilitar el objetivo de servicio universal, entendido como «servicio de calidad a un precio asequible para todos», y a las demás obligaciones de servicio público; al mismo tiempo que se privatizaba la Compañía Telefónica de España, y todas las participaciones del Estado en las compañías eléctricas en un proceso de modernización que ha facilitado la consolidación internacional de las compañías españolas

21 Directiva 2002/21/CE, del Parlamento Europeo y del Consejo, de 7 de marzo de 2002 (LCEur 2002, 1040), relativa a un marco regulador común de las redes y los servicios de comunicaciones electrónicas (Directiva marco), pero también por otras Directivas específicas, en concreto la Directiva 2002/20/CE (Directiva autorización); la Directiva 2002/22/CE (Directiva servicio universal); la Directiva 2002/19/CE (Directiva acceso); y la Directiva 97/66/CE.

22 De la CuÉtARa y A. GonZÁLEZ SANFIEL. «Servicio universal y obligaciones de servicio público en la Ley del Sector eléctrico», Economía Industrial, núm. 316, 1997. 
Hasta el nuevo Tratado de Lisboa de 2007, el Derecho originario no abordaba la cuestión de la competencia sobre la regulación de estas condiciones operativas materiales de servicios público que justificasen la excepción a la libre competencia, quedando en manos de los Estados, a falta de legislación comunitaria específica y sectorial (Directivas, normalmente), definir los requisitos relativos a la cobertura territorial, niveles de calidad y seguridad, derechos de los usuarios o la protección del medio ambiente, y establecer las correspondientes compensaciones sin perjuicio de los poderes de la Comisión ${ }^{23}$. En la aplicación de esta nueva técnica, la Administración se limita a ejercer potestades de regulación y control. Se habla así de una nueva función administrativa o función reguladora ${ }^{24}$. La función de regulación alude al conjunto de poderes de actuación que se ejercitan por órganos especiales, y que proliferan en los distintos ámbitos de la actividad administrativa con la denominación de organismos reguladores de sus respectivos mercados ${ }^{25}$.

La técnica regulatoria se puso al servicio del movimiento privatizador de los servicios económicos de los Estados, en un movimiento que se ha identificado como «despublicatio» ${ }^{26}$; que implica la desaparición del servicio público, como fórmula de organización y gestión de los servicios de redes. Este movimiento privatizador no está exento de crítica; la actuación de la Administración no puede limitarse a la concesión de unas licencias que autoricen a unos determinados operadores la prestación en exclusiva de servicios esenciales, condicionadas a los principios del servicio universal -son las obligaciones generales del servicio esencial ${ }^{27}$-, que carece de la necesaria efectividad si no se acompaña un decálogo de derechos de los usuarios, y además se establecen unos organismos públicos de vigilancia y regulación, al mismo tiempo que se confieren

23 Sobre el problema del rango de tales regulaciones, M.. ${ }^{a}$ Yolanda FernándEZ GARCíA. Op. cit. 14, pág. 135 .

24 J. L. MARTínez LóPEZ-MuÑIZ. «La regulación económica en España», en vol. Col. El nuevo Servicio Publico, Marcial Pons, Madrid 1997, pág. 249.

25 La legislación española ha recogido este concepto de servicio universal. Así la Ley del Sector Eléctrico proclama que abandona la noción de servicio público, tradicional en nuestro ordenamiento pese a su progresiva pérdida de trascendencia en la práctica, sustituyéndola por la expresa garantía del suministro a todos los consumidores usuarios demandantes del servicio dentro del territorio nacional. La Ley General de Telecomunicaciones se limita a decir que «las telecomunicaciones son servicios de interés general que se prestan en régimen de competencia». Del mismo modo, la Ley 2/1997, de 3 de abril, que suprimió los servicios funerarios de entre la lista de servicios que, según el art. 86.3 LRBRL, podían ser municipalizados, declara que los servicios funerarios son «servicios esenciales de interés general», a los que son aplicables los principios de universalidad, continuidad y accesibilidad, sujetando a los operadores en el sector a licencia municipal y a la regulación que el municipio establezca, pudiendo imponer prestaciones forzosas distribuidas por el Ayuntamiento entre las empresas funerarias que operen en el término municipal.

26 Carlos CASSAGNE. «Evolución de los principios aplicables a los servicios públicos y problemas actuales tras los procesos de privatización», RAP, núm. 157, enero-abril de 2002 (CEPC), Madrid.

27 «...aquellas que se establecen de manera singularizada con la finalidad principal de garantizar la generalidad y continuidad del servicio correspondiente o el libre juego de la competencia, y que consisten en prestaciones activas o pasivas que los operadores no asumirían, o no harían en la misma medida ni en las mismas condiciones, si consideraran su propio interés comercial y financiero». 
mayores poderes de representación y defensa a las organizaciones de consumidores y usuarios y se establece un sistema de arbitraje obligatorio que posibilite las reclamaciones. La imposición de obligaciones de servicio público requiere, en primer lugar, delimitar un bloque de prestaciones básicas que deben ser ofrecidas a todos los ciudadanos, cualquiera que sea su rentabilidad y el interés que puedan tener los operadores en prestarlas; en segundo, establecer un sistema equitativo de cargas de servicio público entre todos los operadores que actúan en el sistema; por último, establecer normas sobre costes y su reparto entre los operadores que hayan asumido las cargas, y configurar un adecuado sistema público de seguimiento y control, y por último procedimientos de arbitraje que posibiliten la presentación y tramitación de las reclamaciones de los usuarios ${ }^{28}$.

\section{EL CONCEPTO DE SERVICIO DE INTERÉS GENERAL}

La apertura del proceso liberalizador de servicios públicos de interés económico general discurre en paralelo con un proceso de definición comunitaria del concepto de servicio de interés general que refuerce su posición en el Derecho comunitario. La Comisión, el Parlamento y el Consejo inician la búsqueda de un concepto europeo de servicio de interés general que facilite la compresión del funcionamiento de los sectores público y privado de la economía y, al mismo tiempo, ayude a la definición del alcance de las competencias estatales y comunitarias en la materia.

El primer intento de establecer un concepto homogéneo viene de la mano de la Comunicación de la Comisión sobre «Los servicios de interés general en Europa», de 11 de septiembre de 1996, que rescata el concepto de servicio público esencial y su dimensión genuinamente europea, como parte de los valores comunes de las sociedades de los Estados miembros; lo que aconseja un tratamiento general y común a todos los Estados. Para establecer una verdadera política europea de los servicios públicos, se propone consagrar este concepto en el Tratado, coordinar los órganos nacionales de reglamentación y desarrollar redes europeas.

El Tratado de Amsterdam asume en parte el comunicado de la Comisión e incluye, por primera vez, el concepto de servicio público entre los principios comunitarios, artículo 16 (7 D) TCEE: «Sin perjuicio de los artículos 73, 86 y 87, y a la vista del lugar que los servicios de interés económico general ocupan entre los valores comunes de la Unión, así como de su contribución a la cohesión social y territorial, la Comunidad y los Estados miembros, con arreglo a sus competencias respectivas y en el ámbito de aplicación del presente Tratado, velarán

28 José Luis MARTíneZ MuÑIZ. «En tono a la nueva regulación de los servicios económicos en red», op. cit., núm.19, págs. 251-252. 
SERVICIOS DE INTERÉS GENERAL Y PRINCIPIO DE COMPETENCIA: DEL TRATADO CEE...

por que dichos servicios funcionen con arreglo a principios y condiciones que les permitan cumplir su cometido ${ }^{29}{ }_{\gg}$. El concepto de servicio público se integra en la primera parte del Tratado, como principio estructural de la Comunidad, en cuanto representa los valores de solidaridad, que resultan imprescindibles para la promoción de la cohesión social y territorial. La Comisión no se detiene aquí, con fecha 20 de septiembre de 2000, adopta una segunda Comunicación sobre los Servicios de Interés General en Europa, en un nuevo y renovado esfuerzo por definir los respectivos ámbitos del servicio de interés general y las reglas de la competencia, que a su vez influya en la inminente reforma de los Tratados ${ }^{30}$.

El empeño de la Comisión consigue una mención directa a los servicios de interés general en el artículo 36 de la Carta de los Derechos Fundamentales de la Unión Europea, que figura como una declaración solemne de las instituciones comunitarias anexa al Tratado de Niza, de diciembre de 2000. «La Unión reconoce y respeta el acceso a los servicios de interés económico general, tal como disponen las legislaciones y prácticas nacionales, de conformidad con el Tratado constitutivo de la Comunidad Europea, con el fin de promover la cohesión social y territorial de la Unión ${ }^{31}$. Sin que el artículo 16 del Tratado de Niza modifique o añada alguna nota a la redacción del Tratado de Amsterdam ${ }^{32}$.

El Tratado de Niza y su Carta de Derechos Fundamentales suponen un paso adelante en el reconocimiento de los derechos de acceso general e incondicionado de los ciudadanos a los beneficios y prestaciones de los servicios de interés general y del servicio universal; aunque no establecen un derecho subjetivo y su correspondiente acción o recurso directo a favor de los particulares, la inclusión en la Carta del derecho de acceso al servicio público universal atribuye a los derechos del servicio universal la primacía que corresponde al Derecho comunitario en el ámbito del Tratado, de acuerdo con los niveles de protección que reconocen los artículos 52.1 y 2 , y 53 de la propia Carta. El derecho de acceso a los servicios económicos de interés general goza de la misma protección judicial que los propios Tratados y el Convenio Europeo de Derechos Humanos. Los ciudadanos, según el sistema de recursos de cada Estado, podrán denunciar las regulaciones nacionales y comunitarias del servicio universal y

\footnotetext{
29 Declaración política solemne incorporada al Acta Final, refuerza su posición y explica la evolución posterior: «sus disposiciones se aplicarán con pleno respeto a la jurisprudencia del Tribunal de Justicia, entre otras cosas en lo que se refiere a los principios de igualdad de trato, calidad y continuidad de dichos servicios».

30 Comunicaciones sobre los servicios de interés general [COM (1996) 443 y COM (2000) 580 - Diario Oficial C 281 de 26.9.1996 y Diario Oficial C 17 de 19.1.2001].

31 Los artículos 52 y 53 de la Carta establecen un nivel de protección equivalente al de los propios tratados, de acuerdo con el Convenio Europeo de Derechos Humanos, y del principio de legalidad.

32 «Sin perjuicio de los artículos 73, 86 y 87, y a la vista del lugar que los servicios de interés económico general ocupan entre los valores comunes de la Unión, así como de su papel en la promoción de la cohesión social y territorial, la Comunidad y los Estados miembros, con arreglo a sus competencias respectivas y en el ámbito de aplicación del presente Tratado, velarán por que dichos servicios actúen con arreglo a principios y condiciones que les permitan cumplir su cometido».
} 
de los servicios de interés general, con fundamento en el incumplimiento de los mandatos de la Carta, de acuerdo con la primacía del Derecho comunitario, que desplaza la legislación nacional ${ }^{33}$.

\section{LIBRO VERDE DE LA COMISIÓN, DE 21 DE MAYO DE 2003, SOBRE LOS SERVICIOS DE INTERÉS GENERAL}

La conciliación entre las normas sobre competencia y libertad de movimiento de capitales y personas en la Unión con el mantenimiento de un sector público titular de empresas y de servicios de interés económico general, encargado de la organización y prestación de la mayoría de los servicios sociales y asistenciales: educación, sanidad, asistencia social y pensiones, centrará en parte las iniciativas políticas de la Comisión y del Parlamento Europeo, y el debate político entre los Estados y las instituciones de la Unión Europea, en los 7 años que transcurren desde la aprobación del Tratado de Niza hasta la suscripción del Tratado de Lisboa. En el informe de la Comisión sobre las ayudas estatales relacionadas con los servicios de interés económico general ${ }^{34}$, se propone dar un paso más y definir directamente el concepto y los requisitos de los servicios de interés económico general para esclarecer el alcance de la libertad de configuración de los Estados miembros; el ámbito de aplicación de las normas comunitarias sobre ayudas estatales; las relaciones entre Estados y empresas encargadas de estos servicios (medio propio); las modalidades de selección de las empresas encargadas de los servicios y, fundamentalmente, los medios de financiación del servicio público.

El proyecto de Constitución europea aviva la discusión y pone de manifiesto las distintas posiciones de los Estados sobre el alcance de los servicios económicos de interés general, y sobre el ámbito de decisión a reconocer a los Estados en la definición de los servicios económicos y en los servicios educativos, sociales y asistenciales. La magnitud de la discusión política obliga a la Comisión europea a entrar en el estudio del problema con la redacción de un Libro Verde ${ }^{35}$, que reconoce el alcance de la discusión: «los servicios de interés general se encuentran en el eje del debate político. Afectan a la cuestión central del papel desempeñado por las autoridades públicas en una economía de mercado, a saber, por una parte, velar por el buen funcionamiento del mercado y el respeto de las reglas del juego por todos los protagonistas, y por otra, garantizar el interés general, en particular, la satisfacción de las necesidades esenciales de los ciudadanos y la conservación de los bienes públicos cuando el mercado no lo consigue», y asume la diversidad y complejidad de una mate-

\footnotetext{
33 GonZÁlez CAMPOS y MuÑoz MACHADO. «Las competencias y el funcionamiento del TJCEE. Estudio analítico de los recursos». Tratado de Derecho comunitario. T. Y Madrid 1986. BACIGALUPO M. La Justicia Comunitaria. Estudio sistemático y textos normativos básicos, Marcial Pons, 1995 Madrid.

34 COM (2002) 636 final del 27.11.2002 - no publicado en el Diario Oficial.

35 COM (2003) 270 final - Diario Oficial C 76 de 25.3.2004.
} 
ria que está en constante evolución y que extiende su objeto desde la titularidad y gestión de empresas nacionales en materias de producción industrial directa; los denominados servicios de redes, hasta los servicios educativos en todos los niveles y sus centros de investigación; los hospitales y los sistemas de protección. Lo que dificulta su clasificación y el establecimiento de un concepto de servicio público único ${ }^{36}$.

Los servicios de interés general son el instrumento de las finalidades y justificaciones del poder político; para dificultar su clasificación, se prestan por una extensa red de organismos públicos, según la distribución territorial del poder en cada país, lo que implica una presencia muy diversa de las regiones, estados federados y entes locales en su titularidad y prestación; y admiten diversas formas de gestión y de colaboración público-privada, sin establecer una preferencia por las personificaciones de derecho público - única forma que se corresponde con el canon tradicional de servicio público-, salvo cuando se trata de servicios directamente relacionados con el ejercicio de autoridad, o con el ejercicio directo de los poderes del Estado que tienen relación con su soberanía ${ }^{37}$. Proceso que se ha trasladado a los entes locales de los grandes países de la Unión que, cada vez más, promueven verdaderos grupos empresariales locales o regionales que suplantan la gestión administrativa y reducen el ámbito de función pública ${ }^{38}$.

En este contexto ${ }^{39}$, la Comisión Europea entendió que no era posible presentar una propuesta de Directiva marco sobre los servicios de interés general, sin examinar y someter a debate el alcance de una eventual acción comunitaria conforme al Tratado y en el pleno respeto del principio de subsidiariedad en materia de servicios de interés general; por su parte, el Consejo solicitó su propio estudio y la apertura de un debate previo sobre los aspectos básicos de los servicios de interés general, en especial ${ }^{40}$ :

\footnotetext{
36 El TRATADO DE LISBOA asume expresamente la diferenciación.
}

37 Se mantiene en vigor la vieja distinción entre actos d autoridad y gestión (DUGUIT) que tiene presencia directa en el Reglamento de Servicios de las CCLL de 1955, y en el artículo 92.2 de la vigente Ley 7/85, de 2 de abril, de Bases del Régimen Local.

38 STJCEE Halle, de 11 de enero de 2005 (asunto c-26/03), resuelve esta sentencia las cuestiones prejudiciales que se suscitan en un proceso que tiene como protagonista al Ayuntamiento alemán de Halle y a una de sus sociedades mixtas. Lochau es una sociedad mixta, en la que un empresario privado tiene el $24,9 \%$ de las participaciones y el resto pertenecen a una sociedad municipal de responsabilidad limitada, cuyas participaciones son en su integridad de otra sociedad municipal, que a su vez pertenece también íntegramente al Ayuntamiento.

39 La Comisión se plantea la posibilidad y la conveniencia de establecer una normativa horizontal y general sobre el alcance de las competencias de los poderes públicos para garantizar el buen funcionamiento del mercado y salvaguardar el interés general, se plantea si la liberalización «controlada» de los servicios de redes puede extenderse al resto de los servicios económicos de interés general, a través del mecanismo o técnica del servicio universal, que garantiza el acceso a un servicio de calidad especificada, a un precio asequible, a todos los ciudadanos independientemente de su situación económica, social o geográfica.

40 Propuestas que figuraban en el Informe al Consejo Europeo de Laeken titulado «Servicios de interés general» [COM (2001) 598 - no publicado en el Diario Oficial]. 
1. Los principios que podrían incluirse en una eventual Directiva marco o en otro instrumento general relativo a los servicios de interés general y el valor añadido de un instrumento de esta índole.

2. La definición de buena gobernanza en materia de organización, regulación, financiación y evaluación de estos servicios, a fin de asegurar una economía más competitiva y un acceso eficaz y equitativo de todos los ciudadanos a servicios de calidad que satisfagan sus necesidades.

3. Cualquier medida que pudiera contribuir a reforzar la seguridad jurídica y a garantizar una articulación coherente y armoniosa entre el objetivo de mantener servicios de interés general de calidad y la aplicación rigurosa de las normas sobre competencia y mercado interior.

\section{Alcance la acción comunitaria}

En principio, la actuación de las instituciones de la Unión en materia de servicios de interés económico general debe someterse, como en la mayoría de las políticas comunitarias, a la regla de la subsidiariedad. La Unión carecía de competencias legislativas directas al no existir referencias en los Tratados al establecimiento de un objetivo de servicio de interés general. Su intervención, mientras no exista esta referencia directa, se sostiene en sus grandes títulos competenciales: mercado interior, competencia y ayudas estatales, libre circulación; más las referencias a políticas comunitarias en materia social y medio-ambiental o en materia de salud, protección de los consumidores, establecimiento de redes transeuropeas, industria, cohesión económica y social, investigación, comercio, cooperación al desarrollo, y fiscalidad.

Por lo que se refiere a la mayor o menor intensidad de la acción comunitaria y de los Estados miembros, el Libro Verde define tres categorías de servicios de interés general:

Servicios de interés económico general prestados por grandes industrias de redes (sujetos a regulación armonizada), otros servicios de interés económico general (gestión de residuos, el abastecimiento de agua o los servicios públicos de radiodifusión) que no cuentan con un régimen regulador global de ámbito comunitario, y los servicios de naturaleza no económica y servicios sin efecto en el comercio. La organización, financiación y gestión de estos servicios están sometidas a las normas en materia de mercado interior, competencia y ayudas estatales, siempre que puedan afectar al comercio entre los Estados miembros; por el contrario, los servicios de interés general de naturaleza no económica y los servicios sin efecto en el comercio sólo están al principio de no discriminación e igualdad de acceso. 
En definitiva, la diversidad de servicios y la ausencia de competencias comunitarias en la materia obligan a plantear en el Libro Verde la trascendental cuestión de la inclusión de los servicios públicos entre los objetivos de las Comunidad, y la necesidad de atribuirle competencias específicas en materia de todo tipo de servicios o limitarla a los de naturaleza económica ${ }^{41}$.

\section{Necesidad de establecer un concepto de Derecho comunitario del servicio de interés general}

El Libro Verde somete a debate la posibilidad de una atribución competencial expresa a favor de la Unión en el Derecho originario, y la conveniencia de establecer un concepto comunitario de servicio de interés general que supere definitivamente los problemas del concepto de servicio público y las distintas acepciones de los Estados. En este sentido, se propone codificar en el Derecho originario el concepto de servicio universal con sus notas de puesta a disposición de todos los consumidores con una calidad mínima en todo el territorio de un Estado miembro con independencia de su situación geográfica y, en función de las circunstancias nacionales, a un precio asequible ${ }^{42}$.

\section{Alcance de la discrecionalidad de las autoridades nacionales}

El Libro Verde propone reconocer la discrecionalidad de las autoridades nacionales, regionales y locales para establecer servicios de interés económico general, incluida la competencia para imponer obligaciones a los proveedores de tales servicios, siempre y cuando sean conformes con la normativa comunitaria. Por tanto, a falta de legislación comunitaria específica, corresponde en principio a los Estados miembros definir requisitos relativos al servicio univer$s a$ y los relativos al medio ambiente. Al mismo tiempo, se plantea si la consecución de los objetivos de la Unión impone una definición homogénea de los fines y de los contenidos de servicio público por norma de Derecho comunitario, y así figure en los nuevos Tratados.

\footnotetext{
41 En el mismo sentido, se plantea la necesidad o conveniencia de establecer organismos de regulación a escala continental en los servicios de interés general que ayuden a establecer normativas generales; y la conveniencia de determinar los criterios que permitan distinguir cuando un servicio tiene naturaleza económica o asistencial.

42 Este concepto, acuñado específicamente para ciertas industrias de redes, reconoce a todos los ciudadanos el derecho a acceder a ciertos servicios considerados esenciales e impone a las industrias la obligación de prestar un servicio definido en condiciones especificadas, incluida una cobertura territorial completa. En un entorno de mercado liberalizado, una obligación de servicio universal garantiza que todos los ciudadanos tienen acceso al servicio a un precio asequible, y que se mantiene - y, en su caso, se mejora - su calidad. El concepto de servicio universal tiene carácter dinámico, lo que permite garantizar que los requisitos de interés general tienen en cuenta la evolución política, social, económica y tecnológica y, en su caso, se adaptan regularmente a las necesidades cambiantes de los ciudadanos.
} 


\section{Financiación de los servicios de interés económico general}

La mayoría de los servicios de interés general no se sostienen con el recurso exclusivo al mercado. Los Estados utilizan todo tipo de técnicas para mantener el equilibrio financiero del operador de servicio universal o del medio propio: concesión de ayudas financieras directa a cargo del presupuesto del Estado (subvenciones); o indirectas (desgravaciones fiscales); concesión de derechos especiales o exclusivos (monopolio legal); la imposición de contribuciones de los participantes en el mercado (fondo de servicio universal); y el mecanismo de la equiparación de tarifas o tarifa única aunque existan considerables diferencias en el coste del suministro del servicio. La financiación solidaria, (vía impuestos) se reserva, normalmente, para atender el coste de la seguridad social, la enseñanza y la sanidad públicas.

En este contexto, las normas comunitarias sobre mercado interior, competencia y ayudas estatales tienen por objeto garantizar que cualquier ayuda financiera concedida a servicios de interés económico general no distorsione la competencia y el funcionamiento del mercado interior; sin embargo, se reconoce que la Comisión no cuenta con mecanismos legales efectivos de intervención en la materia, al margen de la Directa sobre transparencia entre los Estados y sus empresas públicas y de las obligaciones dimanantes del Pacto de Estabilidad, ni existen criterios legales más o menos objetivos que posibiliten un examen real del grado de distorsión de la competencia que genera la concesión de ayudas o del grado de sacrificio de los intereses generales que puede generar su prohibición; tampoco se han considerado los efectos de la competencia en la selección de los proveedores de servicios, infraestructuras y suministro a largo plazo. Por todo ello, la Comisión propone abrir un debate sobre la conveniencia de establecer limitaciones a las ayudas públicas, y liberalizar la concesión de ayudas de pequeña cuantía o de cuando se trate de servicios de los entes locales de escasa entidad ${ }^{43}$.

\section{Resolución del Parlamento Europeo, de 13 de enero de 2004, relativa al Libro Verde sobre los servicios de interés general}

El Parlamento europeo declara su satisfacción por el debate abierto por el Libro Verde, emplazando a la Comisión para presentar un informe concluyente antes de finalizar el mes de abril de 2004. La postura del Parlamento europeo, que cada vez ejerce más de motor de la Unión gracias a su naturaleza democrático-representativa directa, en materia de servicios no económicos, es diáfana: la sanidad, la educación, la vivienda social, y los servicios de interés general dirigidos a mantener o promover el pluralismo de la información o la diversidad

\footnotetext{
43 Por primera vez, la Comisión aborda con una visión integral la relación que existe entre el régimen de ayudas públicas, las normas de contratación armonizada, la contratación in house, y las excepciones correspondientes a las misiones de servicio público, en materia de financiación de los servicios económicos de interés general.
} 
cultural deben excluirse del ámbito de aplicación de las normas de competencia. Las iniciativas de la Unión se deben limitar a establecer los principios comunes del servicio público: universalidad, igualdad de oportunidades, continuidad, seguridad, adaptabilidad, calidad, eficacia, accesibilidad de tarifas, transparencia, protección de los grupos sociales desfavorecidos, protección del usuario, del consumidor y del medio ambiente y participación de los ciudadanos. Omitiendo una definición común de tales servicios y de sus concretas obligaciones.

En los servicios de interés económico general se asume la necesidad de compatibilizar las normas de competencia con las obligaciones de servicio público. En materia del ciclo del agua y del tratamiento de residuos, no se deben proponer directivas sectoriales, salvo en materia de contratación y de protección del medio ambiente. En el fondo se viene a reconocer la imposibilidad de alcanzar un acuerdo sobre una lista de servicios de interés general excluidos de la libre competencia, y la especialidad de las materias relacionadas con la gestión del agua y con el tratamiento de residuos.

\section{COMUNICACIÓN DE LA COMISIÓN AL PARLAMENTO EUROPEO, AL CONSEJO, AL COMITÉ ECONÓMICO Y SOCIAL EUROPEO Y AL COMITÉ DE LAS REGIONES, DE 12 DE MAYO DE 2004 «LIBRO BLANCO SOBRE LOS SERVICIOS DE INTERÉS GENERAL»}

El requerimiento del Parlamento y la propia dinámica del debate abierto por el Libro Verde sobre el papel de la Unión Europea en la definición de los servicios de interés general, en relación con la libertad de establecimiento y con el juego de la libre competencia en la prestación de los servicios públicos, fuerzan la redacción de un nuevo Libro (Blanco) ${ }^{44}$, que fija la posición de la Comisión $\mathrm{y}$, a pesar de las dificultades de la empresa, será el punto de partida de cualquier norma de Derecho o iniciativa de Derecho comunitario posterior ${ }^{45}$.

\section{Responsabilidad compartida}

El Libro Blanco está presidido por la necesidad de garantizar una combinación armoniosa de mecanismos de mercado y misiones de servicio público ${ }^{46}$.

\footnotetext{
44 [COM (2004) 374 final - no publicada en el Diario Oficial].

45 Las diferentes posiciones de los Estados sobre la liberalización de los servicios económicos de interés general y, especialmente, sobre la necesidad de introducir el principio de libre competencia en materia de servicios sociales (educación, sanidad, atención a la infancia, juventud vejez, lucha contra la exclusión social), obliga a reconocer la manifiesta imposibilidad de aprobar una propuesta de directiva marco en la materia y sugiere que la Comisión vuelva a examinar la cuestión en una fase posterior.

46 El debate iniciado por el Libro Verde despertó considerable interés y fue favorablemente acogido por muchos de los interesados. La Comisión recibió cerca de 300 contribuciones, procedentes de participantes
} 
Para la Comisión, la división de funciones y competencias entre la Unión y los Estados miembros debe conducir a un reparto de las responsabilidades entre la Unión y las autoridades públicas de los Estados miembros. La definición precisa de los servicios que han de ofrecerse y la prestación de los mismos siguen correspondiendo a los Estados miembros ${ }^{47}$; corresponde a las autoridades nacionales, regionales y locales la definición, organización, financiación y control de tales servicios. Corresponde a la Unión establecer el concepto de servicio de interés general y definir el régimen de ayudas ${ }^{48}$.

Sin embargo, curiosamente, la Comisión no considerara imprescindible atribuir poderes adicionales a la Unión en lo que atañe a los servicios de interés general. Los poderes de la Comunidad serían adecuados y suficientes para garantizar el mantenimiento y desarrollo de servicios eficientes en todo el territorio de la Unión; no obstante, es consciente de la propuesta que figuró en el Proyecto de Constitución: «Sin perjuicio de los artículos III-55, III-56 y III-136, y a la vista del lugar que los servicios de interés económico general ocupan, como servicios a los que en la Unión todos conceden valor, así como de su papel en la promoción de la cohesión social y territorial de ésta, la Unión y sus Estados miembros, con arreglo a sus competencias respectivas y en el ámbito de aplicación de la Constitución, velarán por que dichos servicios actúen con arreglo a principios y condiciones, económicos y financieros en particular, que les permitan cumplir su cometido. Dichos principios y condiciones se definirán mediante leyes europesas», y de la revolución que tal atribución competencial, de aprobarse, puede tener en la distribución de competencias: «Una vez que entre el vigor el Tratado Constitucional, la citada disposición proporcionará un fundamento jurídico adicional a la actuación de la Comuidad en materia de servicios de interés económico general, con arreglo a las competencias de la Unión y en el ámbito de aplicación de la Constitución».

muy diversos, incluidos muchos de los Estados miembros. Los servicios de la Comisión han preparado un Informe sobre la consulta pública, en el que se analizan las contribuciones remitidas y se aporta material de referencia para el presente Libro Blanco. En respuesta a la petición formulada por el Parlamento Europeo en su Resolución sobre el Libro Verde, de 14 de enero de 2004, la Comisión plasma en el Libro Blanco las conclusiones extraídas del debate. El Comité Económico y Social Europeo y el Comité de las Regiones han estudiado asimismo las cuestiones planteadas en el Libro Verde y emitido los correspondientes dictámenes. Dictamen relativo al Libro Verde sobre los servicios de interés general, CESE 1607/2003, 11.12.2003. Dictamen del Comité de las Regiones, de 20 de noviembre de 2003.

47 En consonancia con los principios enunciados en el artículo 16 del Tratado y en el artículo 36 de la Carta de Derechos Fundamentales, la Comisión se ha comprometido a tomar plenamente en consideración el papel específico de los servicios de interés general en las políticas y actividades que se enmarcan en su ámbito de competencia. Velará por que la Unión Europea siga aportando una contribución positiva al desarrollo de los servicios de interés general, que forman parte del modelo europeo, respetando, al mismo tiempo, la diversidad de tradiciones, estructuras y situaciones existentes en los Estados miembros. De acuerdo con los principios de mejora de la legislación1, la evaluación previa del impacto de las iniciativas importantes y la evaluación periódica de las políticas comunitarias pertinentes ayudarán a alcanzar tal objetivo.

48 Esta responsabilidad compartida es el concepto que subyace a lo dispuesto en el artículo 16 del Tratado de Niza, que confía a la Comunidad y los Estados miembros, con arreglo a sus competencias respectivas, la responsabilidad de velar por que sus políticas permitan a los operadores de servicios de interés general cumplir su cometido. 


\section{Objetivo estratégico}

El Libro Blanco asume definitivamente el papel fundamental, que tienen en la Unión Europea los servicios de interés general para garantizar la cohesión social y territorial, y mejorar la competitividad de la economía europea. Los ciudadanos consideran parte esencial de la ciudadanía europea el acceso a servicios de interés general asequibles y de calidad en todo el territorio de la Unión Europea. Por lo que se refiere a las empresas, la disponibilidad de servicios de interés general de calidad constituye una ayuda inestimable para favorecer la competitividad. El suministro de servicios de interés general de calidad, accesibles y asequibles, que respondan a las necesidades de los consumidores y las empresas, es un factor determinante para alcanzar el objetivo estratégico de la Unión de «convertirse en la economía basada en el conocimiento más competitiva y dinámica del mundo, capaz de crecer económicamente de manera sostenible con más y mejores empleos y con mayor cohesión social».

\section{Principios rectores de la política de la Comisión}

El Libro Blanco transcribe los principios rectores de la política de la Unión en materia de servicios de interés general, con la evidente finalidad de servir de guía a las políticas sectoriales de la Comisión y a todas las iniciativas legislativas, incluida la propia reforma constitucional que estaba en marcha. Su influencia en el Tratado de Lisboa es manifiesta.

\section{Facilitar una prestación próxima a los ciudadanos}

Los servicios de interés general se deben prestar y regular a un nivel lo más próximo posible a los ciudadanos y en la necesidad de respetar escrupulosamente el principio de subsidiariedad. La Comisión reconoce el papel esencial de los Estados miembros y de las autoridades regionales y locales en materia de servicios de interés general, que ha de reflejarse en las políticas comunitarias, de conformidad con el principio de subsidiariedad.

\section{Alcanzar objetivos de servicio público en el marco de mercados abiertos y competitivos}

La Comisión considera compatibles la consecución del mercado interior abierto y competitivo y el desarrollo de servicios de interés general accesibles, asequibles y de calidad representan, como se constata con la ampliación de la oferta de servicios en los sectores de telecomunicaciones y transportes. 
Asegurar la cohesión y el acceso universal

La cohesión social y territorial en la Unión Europea es un compromiso de la Unión, es imprescindible permitir a todos los ciudadanos y empresas el acceso a servicios de interés general asequibles y de calidad en todo el territorio de los Estados miembros. La Comisión está comprometida en la mejorara del acceso universal efectivo a los servicios de interés general a través de todas sus políticas.

\section{Mantener un alto nivel de calidad, fiabilidad y seguridad}

Las políticas comunitarias deben facilitar el mantenimiento de los niveles de calidad, fiabilidad y seguridad exigibles en un mercado abierto. Lo que exige una evaluación periódica, y tomar en consideración el papel de los servicios de interés general en la protección del medio ambiente, especialmente, los relacionados con el agua y el tratamiento de residuos.

\section{Garantizar los derechos de los consumidores y usuarios}

La Comisión asume y entiende la necesidad de organizar la prestación de los servicios de interés general de modo que se garanticen, al máximo, los derechos de los consumidores y usuarios.

\section{Controlar y evaluar el funcionamiento de los servicios}

A la vista de los resultados de la consulta pública, la Comisión se manifiesta convencida de que sin evaluación y control no se cumplen los requisitos de calidad, accesibilidad, y eficiencia requerida a los servicios en la Unión Europea.

\section{Respetar la diversidad de servicios y de situaciones}

La Comisión asume la existencia de diferencias acusadas entre los distintos servicios de interés general; y la existencia de situaciones diferentes en las necesidades y en las preferencias de los consumidores y usuarios, según las diversas situaciones económicas, sociales, geográficas o culturales. Por el carácter personal y humanitario de numerosos servicios sociales y sanitarios reconoce que no son equiparables a las industrias de red. En lo que respecta a la radiodifusión, debe tenerse presente su importancia decisiva para garantizar y preservar la pluralidad que requiere la democracia, y satisfacer las necesidades sociales y culturales de cualquier sociedad. 
SERVICIOS DE INTERÉS GENERAL Y PRINCIPIO DE COMPETENCIA: DEL TRATADO CEE...

\section{Aumentar la transparencia}

El principio de transparencia es el fundamental para asegurar y garantizar el acierto de las decisiones libremente adoptadas. La Comisión entiende que debe aplicarse a todos los aspectos del proceso de prestación de servicios de interés general; desde la fase de definición de las misiones de servicio público y de los modelos de organización, financiación y regulación de los servicios; hasta la evaluación de la prestación y la resolución de reclamaciones.

\section{Proporcionar seguridad jurídica}

La Comisión comparte la necesidad de clarificar la normativa comunitaria, en especial en materia de ayudas estatales a la financiación de servicios de interés general y a las normas relativas a la contratación pública de obras, servicios y suministros. Y de la especialidad de los servicios sociales y sanitarios. La Comisión era consciente de los complejos problemas que plantea la aplicación del Derecho comunitario a los servicios de interés general, y de la imposibilidad de adoptar una norma o Directiva marco en la materia mientras se mantengan las dudas de los Estados y no se apruebe la reforma constitucional. En el marco de tal examen, la Comisión se compromete a someter toda propuesta a una evaluación de impacto previa que permita determinar sus repercusiones económicas, sociales y ambientales.

\section{Clarificar y simplificar el marco legal referente a la compensación de las obligaciones de servicio público}

El debate abierto por el Libro Verde confirma la necesidad de una mayor previsibilidad y seguridad jurídica en la aplicación de las normas sobre ayudas estatales a la compensación por prestación de servicio público. A pesar de existir una doctrina consolidada del Tribunal de Justicia en materia de ayudas y compensaciones públicas por servicios de interés económico general ${ }^{49}$, para la Co-

\footnotetext{
49 Sentencia de 24 de julio de 2003 en el asunto C-280/00, Altmark Trans, núm. 89 «En primer lugar, la empresa beneficiaria debe estar efectivamente encargada de la ejecución de obligaciones de servicio público y éstas deben estar claramente definidas.

90 En segundo lugar, los parámetros para el cálculo de la compensación deben establecerse previamente de forma objetiva y transparente.

91 Así, constituye una intervención financiera incluida en el concepto de ayuda de Estado en el sentido del artículo 92, apartado 1, del Tratado, la compensación por parte de un Estado miembro de las pérdidas sufridas por una empresa sin que se hayan establecido previamente los parámetros de tal compensación, cuando, "a posteriori», se comprueba que la explotación de determinados servicios en el marco de la ejecución de obligaciones de servicio público no ha sido económicamente viable.

92 En tercer lugar, la compensación no puede superar el nivel necesario para cubrir total o parcialmente los gastos ocasionados por la ejecución de las obligaciones de servicio público, teniendo en cuenta los ingresos correspondientes y un beneficio razonable por la ejecución de estas obligaciones.
} 
misión es necesario promover una mayor seguridad jurídica, y una mayor transparencia en las relaciones de los poderes públicos con sus empresas prestadoras de servicios modificando la Directiva transparencia de 198050; para completar las medidas, se compromete a presentar adicionalmente una Decisión sobre compatibilización de las ayudas públicas de pequeño importe a favor de servicios de interés económico general, estas ayudas quedarán también exentas de la obligación de notificación previa, siempre que guarde proporción con el coste efectivo de los servicios y que no se superen determinados límites máximos establecidos. Por último, la Comisión propone extender el mismo planteamiento a la financiación de los servicios de interés general que prestan los hospitales y los organismos de vivienda social, con independencia del importe de la misma.

\section{Establecer un marco claro y transparente para la selección de las empresas encargadas de prestar un servicio de interés general}

La comisión detecta el recurso creciente a fórmulas de colaboración público-privada para el diseño-construcción-financiación-explotación, de todo tipo de obras y concesiones de servicios públicos susceptibles de explotación económica, y la creación de empresas de economía mixta, para la ejecución de proyectos de infraestructura o la prestación de servicios de interés general, abandonándose la gestión directa ${ }^{51}$. Para afrontar las dificultades que suponen estas nuevas fórmulas de colaboración público privada, y la excepción a la competencia que supone la doctrina del medio propio ${ }^{52}$, coincidiendo con la presentación del Libro Blanco, la Comisión promovió la Directiva 18/2004, de

93 En cuarto lugar, cuando la elección de la empresa encargada de ejecutar obligaciones de servicio público, en un caso concreto, no se haya realizado en el marco de un procedimiento de contratación pública que permita seleccionar al candidato capaz de prestar estos servicios originando el menor coste para la colectividad, el nivel de la compensación necesaria debe calcularse sobre la base de un análisis de los costes que una empresa media, bien gestionada y adecuadamente equipada en medios de transporte para poder satisfacer las exigencias de servicio público requeridas, habría soportado para ejecutar estas obligaciones, teniendo en cuenta los ingresos correspondientes y un beneficio razonable por la ejecución de estas obligaciones».

STJCE, de 24 de noviembre de 2003, en los asuntos acumulados C-34/01 a 38/01.

50 Asimismo, la Comisión se propone modificar la Directiva 80/723/CEE relativa a la transparencia de las relaciones financieras entre los Estados Miembros y las empresas públicas. La modificación tiene por objeto precisar que la Directiva es aplicable a las compensaciones por servicio público, cualquiera que sea su calificación jurídica con arreglo al artículo 87 del Tratado. Ni la decisión de la Comisión ni el marco comunitario serán de aplicación en el sector del transporte.

51 Esta posición de la Comisión y las declaraciones del Libro Blanco sembraron la duda sobre el alcance de las competencias estatales para organizar sus propios servicios y empresas de interés económico general, y definen una posición de la Comisión abiertamente decidida por extender la liberalización a todos los sectores de la actividad publica.

52 Por lo que respecta al transporte interno local, la Comisión ha presentado propuestas por las que se obligaría a los Estados miembros a recurrir a concesiones de servicio público. Véase la propuesta modificada de Reglamento del Parlamento Europeo y del Consejo sobre la intervención de los Estados miembros en materia de obligaciones de servicio público y adjudicación de contratos de servicio público en el transporte de viajeros por ferrocarril, carretera y vía navegable, DO C 151 E de 25.6.2002. 
SERVICIOS DE INTERÉS GENERAL Y PRINCIPIO DE COMPETENCIA: DEL TRATADO CEE...

31 de marzo, de coordinación de los procedimientos de adjudicación de los contratos de obras, suministros y servicios (que ha unificado y reformado las Directivas anteriores), y la Directiva 17/2004, de 31 de marzo, de coordinación de los contratos en los sectores del agua, la energía, los transportes y los servicios postales. La obligación de incorporación al ordenamiento interno de los Estados miembros se fijaba para el mes de enero de $2006^{53}$. Su entrada en vigor debe contribuir a conseguir el objetivo de transparencia en la contratación pública impuesto por el Tratado CE.

La aprobación de las nuevas Directivas, unida a las declaraciones del Libro Blanco de los servicios de interés general, y a la propia política de la Comisión, decidida a aplicar íntegramente los nuevos procedimientos de contratación a todos los servicios de interés general, empresas y organismos públicos, para una buena parte de la doctrina científica ${ }^{54}$, ponen en riego la existencia de todo tipo de empresas y entidades creadas por las autoridades públicas para atender una finalidad de interés económico general. De prosperar una mal entendida aplicación generalizada de la transparencia y de la aplicación de las reglas de contratación a las relaciones entre los poderes públicos y sus empresas instrumentales, como parece propugnar el Libro Blanco y la literalidad de la Directivas, los poderes públicos quedan sometidos como cualquier particular a los imperativos y dictados del derecho de la competencia, y a los pies de la Comisión que debería autorizar las sucesivas contrataciones y encomiendas de gestión. Lo que supondría una privatización obligada de todas las empresas públicas, y el abandono de toda la doctrina del TJCE sobre la teoría del medio propio $^{55}$ recientemente reiterada para el Reino de España por la $c-295 / 05$, de 19 de abril de 2007, asunto TRAGSA.

A pesar del rechazo de estas tesis, hay que reconocer que las relaciones entre las Administraciones Públicas y sus entes instrumentales, en materia de transparencia y ayudas públicas, eran la gran asignatura pendiente de los servicios de interés general. Si una interpretación de la Directiva 18/2004, sobre procedimientos de contratación armonizada, amenaza la supervivencia de todo el sector

\footnotetext{
53 España las ha incorporado con dos años de retraso, con apercibimiento de sanción, al cierre de la legislatura con una gran esfuerzo parlamentario que ha permitido aprobar la Ley 30/2007, de Contratos del Sector Público, y con apercibimiento de incumplimiento

54 Sosa WAGNER, F. «El empleo de recursos propios por las Administraciones locales», Estudios de Derecho público económico». Libro homenaje al prof. S. Martín Retortillo, Madrid, 2003, págs. 1309 y ss.; REBOLLO PUIG, M. «Los entes institucionales de la Junta de Andalucía y su utilización como medio propio», RAP, núm. 163, págs. 245 y ss.; HUERGO, A. «La libertad de empresa y la colaboración preferente de las Administraciones con empresas públicas», op. cit. núm. 22; ORTIZ MALLOL, J. «La relación de dependencia de las entidades instrumentales de la Administración pública: algunas notas», RAP, núm. 163, págs. 245 y ss.

55 STJCEE de 18 de noviembre de 1999 (c-107/98) conocida comúnmente como Sentencia Teckal. Ante la impugnación que una empresa privada realizó del contrato entre un Ayuntamiento y una Azienda consorziale, el Tribunal admitió que es posible excluir la aplicación de las directivas de contratos públicos cuando se contrata con una entidad: «en el supuesto de que, a la vez, el ente territorial ejerza sobre la persona de que se trate un control análogo al que ejerce sobre sus propios servicios y esta persona realice la parte esencial de su actividad con el ente o los entes que la controlan».
} 
público; esto no implica la renuncia a una regulación comunitaria horizontal, que determine el régimen de ayudas posibles a los servicios de interés general, y el concepto de medio propio que justifica la exclusión de la regla de la competencia, de acuerdo con la doctrina del Tribunal de Justicia de Luxemburgo ${ }^{56}$.

El mantenimiento, adaptación y modernización de los servicios sociales y sanitarios también tiene relación directa con la consecución de los objetivos fijados por el Consejo Europeo de Lisboa en marzo de 2000; especialmente, con el objetivo de crear un vínculo positivo entre las políticas económica, social y de empleo. La Comisión, a la vista de las propuestas presentadas en los debates abiertos por el «Libro Verde», entiende que existe un manifiesto interés de las empresas de servicios sociales para iniciar un proceso de modernización que les permita adaptarse a las necesidades cambiantes de los ciudadanos europeos, condicionado a que se aprueba un escenario y un calendario de actuaciones necesario para afrontar la ingente inversión que requiere la modernización de los servicios sociales y los sanitarios, que sólo puede alcanzarse con una privatización parcial de tales servicios.

La Comisión reconoce que corresponde a los Estados miembros definir las funciones y objetivos de los servicios sociales y sanitarios, aunque expresa su confianza en los efectos de la normativa comunitaria sobre la mejora de los instrumentos de prestación y financiación de dichos servicios ${ }^{57}$; a estos efectos, la Comisión se compromete a presentar una Comunicación sobre los servicios sociales y sanitarios de interés general en el transcurso de 2005, y a facilitar la cooperación en materia de servicios sanitarios entre los Estados miembros.

\section{Analizar los resultados y evaluar el funcionamiento de los servicios}

La Comisión asume la necesidad de modificar y racionalizar la metodología estadística, facilitar y promover la participación de todos los interesados: autoridades públicas, consumidores y usuarios, los proveedores y los trabajadores, en todos los procesos de liberalización, y en el examen de sus consecuencias para los ciudadanos, las empresas y los trabajadores. Las tareas de evaluación deben realizarse con mayor alcance.

\section{Revistar las políticas sectoriales}

La Comisión abandona la iniciativa de una Directiva marco de los servicios de interés económico general, y ratifica el sistema de reglamentación sectorial

\footnotetext{
56 STJCE, de 24 de julio de 2003 en el asunto C-280/00, Altmark Trans, Op. cit 81, Y SSTJCEE Halle, de 11 de enero de 2005 (asunto c-26/03), y Mödling, de 10 de noviembre de 2005. asunto c-29/04.

57 Libro Verde sobre la colaboración público-privada y el Derecho comunitario en materia de contratación pública y concesiones, COM(2004) 327, de 30.4.2004
} 
SERVICIOS DE INTERÉS GENERAL Y PRINCIPIO DE COMPETENCIA: DEL TRATADO CEE...

para extender la política de liberalización y privatización de las grandes industrias de red al resto de los sectores, sobre los que se aplicarán los valores y los contenidos del servicio universal, tal como figuran en el Libro Verde: continuidad, calidad, accesibilidad, protección de los consumidores y usuarios, seguridad y fiabilidad ${ }^{58}$, e interconectividad.

Garantizar que nuestra política comercial internacional sea el reflejo de nuestras políticas internas

La Comisión insiste en la necesidad de coordinar los compromisos alcanzados por la Unión en las conferencias de la Organización Mundial del Comercio (OMC) con las normas sobre mercado interior aplicables a los servicios de interés general, para evitar problemas y limitaciones a la libertad de organización, prestación y financiación de dichos servicios. No obstante, hay que advertir que los servicios de interés general implican una posición de reserva en materia de liberalización del comercio mundial, que beneficia la posición de los Estados con mayor nivel de renta, que excluyen una buena parte de sus actividades económicas de la competencia mundial.

\section{Promover servicios de interés general en la cooperación para el desarrollo}

El debate abierto por el Libro Verde puso de relieve la importancia que revisten los servicios básicos de interés general para el desarrollo de los países más pobres, y la manifiesta necesidad de fondos para atender la inversión necesaria para su mejora. De acuerdo con las recomendaciones formuladas en la Comunicación de la Comisión sobre la reforma de las empresas públicas en los países en desarrollo, se propone continuar contribuyendo a la implantación de un marco su reforma, con especial atención a los servicios públicos ${ }^{59}$.

\section{COMUNICACIÓN DE LA COMISIÓN, DE 26 DE ABRIL DE 2006, «APLICACIÓN DEL PROGRAMA COMUNITARIO DE LISBOA. SERVICIOS SOCIALES DE INTERÉS GENERAL EN LA UNIÓN EUROPEA»}

La Comunicación ${ }^{60}$ sobre los servicios sociales de interés general asume las dificultades de los procesos de privatización y la imposibilidad de aprobar una

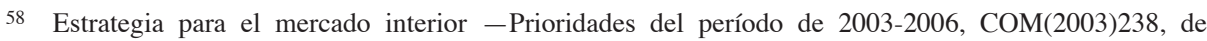
7.5.2003

59 Comunicación de la Comisión, $\operatorname{COM}(2003)$ 326, de 3.6.2003.

60 Servicios sociales de interés general en la Unión Europea» COM (2006) 177 final - no publicada en el Diario Oficial.
} 
Directiva en la materia; para superar esta situación, siguiendo las propuestas del Libro Blanco y de la Agenda Social europea, afronta una definición separada de los de servicios sociales y sanitarios, que intente definir un marco común que facilite su modernización. Teniendo en cuenta que son servicios de plena competencia estatal, aunque se puedan ver afectados por la fuerza expansiva de los grandes principios de los Tratados.

La Comisión asume el papel específico y diferenciado que desempeñan los servicios sociales en los Estados definidos por el principio de solidaridad ${ }^{61}$. Al mismo tiempo constata que lejos de encontrarnos ante situaciones marginales y en retroceso, estamos inmersos en un proceso de expansión de los servicios sociales, que requiere una modernización inmediata de sus técnicas de gestión, entre otras:

- Introducción de métodos de «evaluación comparativa» (benchmarking) y de control de calidad y la participación de los usuarios en la gestión;

- Descentralizar la organización con el establecimiento de servicios a nivel local o regional;

- La externalización de las tareas del sector público, que se encargan al sector privado aunque en las condiciones de competencia reguladas por las autoridades públicas;

- Desarrollar marcos de colaboración entre los sectores público y privado y el recurso a otras formas de financiación complementarias de la pública.

La Comunicación termina con el compromiso de consultar a todos los actores interesados: Estados miembros, suministradores de servicios y usuarios sobre las características propias de los servicios sociales, así como su pertinencia para definir la especificidad de esos servicios cuando son de interés general; la forma en que los Estados miembros puedan tener en cuenta esas características al definir las misiones de interés general; la experiencia adquirida con la aplicación del Derecho comunitario en el ámbito de los servicios económicos de interés general y los posibles problemas surgidos en este contexto. En resumen, la Comisión acepta y asume la distinción entre las categorías de servicios (económicos) de interés general, y servicios sociales y sanitarios, impuesta por las declaraciones del Parlamento, y la necesidad de compatibili-

\footnotetext{
61 Para la Comisión, tienen las siguientes características: Un funcionamiento basado en el principio de solidaridad; un carácter polivalente y personalizado que atiende a los diversos aspectos que son necesarios para garantizar los derechos humanos fundamentales y proteger a las personas más vulnerables; ausencia de ánimo de lucro; participación de voluntarios; un profundo enraízamiento en una tradición cultural local; esto se refleja de forma especial en la proximidad que existe entre el prestador del servicio y el beneficiario; una relación entre el prestador del servicio y el beneficiario que, siendo asimétrica, no puede compararse con la que existe «normalmente» entre suministradores y consumidores.
} 
zar el mercado interior de los servicios con el modelo social europeo. Y abandona las políticas privatizadoras a ultranza que ya no se contemplan como una panacea, pero no renuncia a introducir fórmulas de colaboración privada en la gestión de los servicios sociales, culturales y sanitarios, que siguen en manos de las Administraciones Públicas y se prestan por organismos públicos ${ }^{62}$. A la postre, la identificación que existe entre los servicios sanitarios y sociales y el propio concepto de Estado social y democrático explican el paréntesis abierto por la Comisión y la propia posición de los Estados, que están mucho más empeñados en lanzar políticas de calidad (cartas de servicios, formación de directivos, análisis de los servicios administrativos y propiamente prestacionales) que en definir proyectos de privatización ${ }^{63}$.

\section{DIRECTIVA 2006/111/CE DE LA COMISIÓN DE 16-11-2006}

Entre las preocupaciones de la Comisión que se detallan en el Libro Blanco de los Servicios de Interés General destaca la aplicación del principio de transparencia a las relaciones financieras de los poderes públicos con sus empresas y sus servicios económicos dependientes. Para la Comisión es imprescindible establecer «el marco legal referente a la compensación de las obligaciones de servicio público de las empresas con derechos especiales o exclusivos, y de las empresas de titularidad pública, en general. En ausencia de armonización a nivel comunitario, el principal límite al poder discrecional de los Estados viene marcado por la condición de que el mecanismo de financiación no falsee la competencia en el mercado común.» Sin que sea fácil determinar en qué condiciones la compensación por servicios de interés económico general, o la concesión de derechos especiales o exclusivos a estas o a otras empresas constituye efectivamente ayuda estatal ${ }^{64}$. Para superar esta situación, la Comisión se obliga a modificar, antes del mes de julio de 2005, la Directiva 80/723/CEE relativa a la transparencia de las relaciones financieras entre los Estados Miembros y las empresas públicas, para extender las obligaciones de información y control a todo tipo de compensaciones y ayudas con fondos públicos a favor de toda

62 Comunicación de la Comisión titulada «La Agenda social» COM (2005) 33 final - no publicada en el Diario Oficial. La Comisión Europea propone en esta Comunicación una nueva agenda social para el período 2006-2010. El principal objetivo de dicha agenda es poner en marcha en el marco de la economía mundial una Europa social creadora de empleos y de nuevas oportunidades para todos

63 La Unión Europea cuenta con el Plan de Acción eEurope 2005, y promovió (1988) la Fundación Europea para la Gestión de la Calidad (E.F.Q.M.), con el fin de reforzar la posición de las empresas europeas en el mercado mundial impulsando en ellas la Calidad como factor estratégico clave para lograr una ventaja competitiva global.

64 Ap. 4.2 Libro Blanco SIG: La consulta pública ha confirmado la demanda de una mayor previsibilidad y seguridad jurídica en la aplicación de las normas sobre ayudas estatales a la compensación por prestación de servicio público, demanda que ha sido particularmente enérgica a nivel local, en relación con los servicios locales.» 
clase de entidades y empresas públicas, cualquiera que sea su calificación jurídica con arreglo a los artículos 86 y 87 del Tratado ${ }^{65}$.

\section{Alcance de las medidas de información y control}

La Directiva 2006/111/CE de la Comisión, de 16 de noviembre de 2006 66 , de modificación de la Directiva 80/723/CEE de la Comisión, de 25 de junio de 1980, relativa a la transparencia de las relaciones financieras entre los Estados miembros y las empresas públicas, es una medida imprescindible para racionalizar y aclarar el sistema legal de ayudas públicas a favor de los servicios de interés general y empresas con derechos especiales o exclusivos, conocer la facturación de estas entidades y su importe efectivo en porcentaje sobre el PIB de los Estados, y determinar su influencia real sobre la competencia. Se trata de evitar los abusos de las empresas que tengan concedidos esos derechos especiales o exclusivos o estén encargadas de la gestión de servicios de interés económico general, que reciban cualquier tipo de compensación por el servicio público y que realicen también otras actividades, así como controlar las relaciones financieras existentes entre las empresas públicas y las Administraciones públicas ya sean de ámbito estatal, autonómico o local, para garantizar la transparencia financiera de estas relaciones en la gestión de un servicio de interés económico general o la realización de actividades en virtud de la concesión por parte de dichas Administraciones públicas, de derechos especiales o exclusivos a cualquier empresa, siempre que ésta realice otras actividades distintas a las anteriores.

Los Estados miembros informarán con el detalle requerido sobre las puestas a disposición de fondos públicos, por cualquier medio, a las empresas públicas de que se trate; y sobre la utilización efectiva de esos fondos públicos.

\section{Concepto de empresa pública}

El concepto de empresas pública se predica de aquellas sobre la que los poderes públicos puedan ejercer, directa o indirectamente, una influencia dominante en razón de la propiedad, de la participación financiera o de las normas que la rigen ${ }^{67}$.

\footnotetext{
65 Como medidas adicionales, se compromete a adoptar una Decisión sobre la aplicación del artículo 86 del Tratado a las ayudas estatales consistentes en la concesión de compensaciones por servicio público a determinadas empresas a las que se haya confiado la gestión de servicios de interés económico general.

66 El Estado español cumplió con su obligación de incorporación por Ley 4/2007, de 3 de abril, de transparencia de las relaciones financieras entre las Administraciones públicas y las empresas públicas, y de transparencia financiera de determinadas empresas.

67 Se presumirá que hay influencia dominante cuando, en relación con una empresa, el Estado u otras administraciones territoriales, directa o indirectamente:
} 
SERVICIOS DE INTERÉS GENERAL Y PRINCIPIO DE COMPETENCIA: DEL TRATADO CEE...

La Directiva tiene la virtud y el mérito de definir y sistematizar las distintas menciones de empresas y servicios que figuraban en el artículo 86 del Tratado:

Derechos exclusivos: Se entiende por tales, a los concedidos por un Estado miembro a una empresa mediante cualquier instrumento legal, reglamentario o administrativo que reserve a esta empresa el derecho a prestar un servicio o emprender una actividad en una zona geográfica específica. Se trata de la reserva en monopolio de indudable trascendencia en el ámbito local;

Derechos especiales: Los derechos concedidos por un Estado miembro a un número limitado de empresas mediante cualquier instrumento legal, reglamentario o administrativo que, en una zona geográfica específica: i) limite a dos o más el número de esas empresas autorizadas a prestar un servicio o emprender una actividad, con criterios que no sean objetivos, proporcionales y no discriminatorios, o ii) designe, con arreglo a tales criterios, a varias empresas autorizadas a prestar un servicio o emprender una actividad, o iii) conceda a una o varias empresas, con arreglo a tales criterios, ventajas legales o reglamentarias que afecten sustancialmente a la capacidad de cualquier otra empresa de prestar el mismo servicio o ejercer la misma actividad en la misma zona geográfica en condiciones sustancialmente equivalentes. Evidentemente, se trata del denominado servicio reglamentado;

Empresa obligada a llevar cuentas separadas: Cualquier empresa a la que un Estado miembro haya concedido derechos especiales o exclusivos con arreglo al artículo 86, apartado 1, del Tratado, o a la que se haya confiado la gestión de un servicio de interés económico general con arreglo al artículo 86, apartado 2, del Tratado, que reciba cualquier tipo de compensación por servicio público en relación con tal servicio y que realice otras actividades; deberá presentar cuentas separadas por las «diferentes actividades», diferenciando los costes y los rendimientos de los servicios de interés económico general que se hayan confiado a una empresa del resto. Los Estados garantizarán que la estructura financiera y organizativa de cualquier empresa que esté obligada a llevar cuentas separadas se refleje correctamente en dichas cuentas, de manera que aparezcan claramente indicados: a) los costes e ingresos derivados de las diferentes actividades; b) información detallada sobre los métodos de asignación o distribución de los costes e ingresos entre las diferentes actividades.

i) posean la mayoría del capital suscrito de la empresa, o ii) dispongan de la mayoría de los votos correspondientes a las participaciones emitidas por la empresa, o iii) puedan designar a más de la mitad de los miembros del órgano de administración, de dirección o de vigilancia de la empresa; c) «empresas públicas que operan en el sector manufacturero», todas las empresas cuya principal área de actividad, definida como aquella que representa al menos el 50\% de su volumen de negocios global anual, sean las manufacturas; estas empresas son aquellas cuyas operaciones corresponden a la sección D, «Industria manufacturera», que incluye de la subsección DA hasta la subsección DN, de la clasificación NACE. 
Empresas manufactureras: Para las empresas manufactureras que han sobrevivido a los procesos de privatización de las sucesivas crisis y siguen con su actividad industrial o comercial plenamente insertada en el mercado, la Directiva regula, en los artículos 7 y 8 , las obligaciones especiales de suministro de información anual a la Comisión, y los supuestos especiales de acceso, seguridad y objeto y detalle de la participación pública en la financiación ${ }^{68}$. Se entenderá por empresas públicas que realizan su actividad principal en el sector manufacturero si obtiene ingresos de carácter periódico que representan al menos el 50 por ciento del importe neto de su cifra de negocios, sea la transformación mecánica, física o química de materiales, sustancias o componentes en nuevos productos ${ }^{69}$.

\section{Modalidades y tipos de ayudas}

Las relaciones financieras entre los poderes públicos y las empresas públicas cuya transparencia ha de quedar garantizada son:

a) la compensación de las pérdidas de explotación; b) las aportaciones en capital o en dotación; c) las aportaciones a fondo perdido o los préstamos en condiciones privilegiadas; d) la concesión de ventajas financieras en forma de renuncia a beneficios o de no recuperación de créditos; e) la renuncia a una remuneración normal de los fondos públicos comprometidos; f) la compensación de las cargas impuestas por los poderes públicos.

Los Estados miembros adoptarán las medidas necesarias para que se asignen o distribuyan correctamente todos los costes e ingresos de las empresas obligadas a llevar cuentas separadas por actividades, de acuerdo con los princi-

68 Artículo 14 de la Ley 4/2007. Las empresas públicas que cumplan la definición del artículo 14 de esta Ley, y siempre que el importe neto de su cifra de negocios en el ejercicio anterior haya sido superior a 250 millones de euros, habrán de remitir a la Intervención General de la Administración del Estado dentro de los siete meses siguientes a la terminación del ejercicio económico, la información recogida en el presente artículo. Cuando se trate de empresas públicas autonómicas y locales el envío de la información anterior se efectuará por conducto del órgano competente de la Comunidad Autónoma o de la Entidad Local.

4. La información que deberá remitirse comprenderá los siguientes documentos:

a) Las cuentas anuales y el informe de gestión individuales y, en su caso, consolidados, que deban elaborarse de acuerdo con lo dispuesto en la normativa contable que les sea de aplicación. Además, deberán adjuntarse las actas de las juntas generales de accionistas.

b) Sin perjuicio de la información que deba suministrarse en la memoria de las cuentas anuales individuales y, en su caso, consolidadas, en un anexo que no formará parte de éstas, y que no será objeto de publicación, se incluirá la información relativa a:

- Cualquier tipo de intervención pública, en particular, la condonación de cantidades adeudadas a las Administraciones públicas por la empresa pública, incluidos, entre otros, el reembolso de préstamos, las subvenciones, el pago del Impuesto sobre Sociedades, las cotizaciones sociales y otros pagos de carácter similar.

69 La influencia de las normas SEC sobre la integración en el sector público del posible déficit es palmaria. 
SERVICIOS DE INTERÉS GENERAL Y PRINCIPIO DE COMPETENCIA: DEL TRATADO CEE...

pios de contabilidad de costes aplicados de forma objetiva y coherente. Adoptarán las medidas necesarias para que los datos relativos a las relaciones financieras mencionadas en el artículo 1, apartado 1, permanezcan a disposición de la Comisión durante cinco años desde el final del ejercicio anual durante el cual los fondos públicos hayan sido puestos a disposición de las empresas públicas de que se trate.

\section{4. Ámbito de aplicación y exclusiones}

La Directiva no se aplica a las relaciones financieras que no afecten de forma apreciable al comercio entre los Estados miembros. Se excluyen los bancos centrales; las entidades de crédito públicas, por lo que se refiere a los depósitos de fondos públicos efectuados por los poderes públicos en condiciones comerciales normales; y las empresas públicas cuyo volumen de negocios global neto anual en los dos ejercicios anuales anteriores al ejercicio en que se hayan puesto a disposición o utilizado los fondos mencionados en el artículo 1, apartado 1, haya sido inferior a 40 millones de euros. Si se trata de entidades de crédito públicas, el umbral se sitúa en un balance total de 800 millones.

Como demostración de la relación existente entre las normas sobre transparencia y sobre contratación pública, no será necesario aplicar esta Directiva a las empresas a las que se haya confiado la gestión de servicios de interés económico general a efectos del artículo 86, apartado 2, del Tratado, siempre que las compensaciones que reciban, cualquiera que sea cual sea la forma utilizada, se haya fijado por un período apropiado con arreglo a un procedimiento abierto, transparente y no discriminatorio.

La Comisión Europea dispone ahora de un instrumento de suministro de información que nos permitirá conocer a todos el verdadero ámbito de los servicios de interés general y de los servicios o empresas con derechos exclusivos o especiales en todos los Estados miembros, y la supervivencia de las empresas manufactureras, así como el importe de las ayudas directas o indirectas que sostienen las prestaciones de los servicios de interés general. Información que permitirá adoptar una legislación comunitaria armonizadora de alcance general o por sectores.

\section{TRATADO DE LISBOA DE 13 DE DICIEMBRE DE 2007}

El Tratado de Lisboa es la última modificación de los tratados de las Comunidades europeas que han firmado solemnemente en Lisboa los jefes de Estado o Gobierno con fecha, 13 de diciembre de 2007. Sucede al Tratado de Niza de 2001, que mantiene transitoriamente el sistema de mayorías vigentes en este 
momento ${ }^{70}$, y sustituye al Tratado de la Constitución Europea que se ratificó por 19 de los 27 Estados miembros de la Unión Europea, España entre ellos, sin llegar a entrar en vigor por el resultado negativo de los referendum francés y holandés, que paralizó el proceso en los otros siete Estados, que ni siquiera lo sometieron a ratificación. Por primera vez en la historia de la integración europea, un Tratado modificativo que instauraba formas estatales en las instituciones comunes, y una mayor cesión nominal de soberanía, no obtuvo la necesaria ratificación de los ciudadanos franceses y holandeses ${ }^{71}$. En la conferencia intergubernamental promovida por Alemania para los días 22 y 23 de junio de 2007, tras dos años de parálisis, dudas y reflexiones, se decide abandonar formalmente el Tratado Constitucional e iniciar un procedimiento rápido de reforma, que salvara las cuestiones menos discutidas del citado Tratado Constitucional ${ }^{72}$. El nuevo Tratado parte de un mandato cerrado del Consejo que sustituye a la fallida Constitución por un doble texto que sigue siendo excesivamente complejo, junto con el texto de los dos Tratados (Unión Europea y Tratado de Funcionamiento), está integrado por 11 Protocolos nuevos anexos a los Tratados, que se unen a los 31 que subsisten, junto con unas tablas de correspondencias; 43 Declaraciones relativas a disposiciones de los Tratados; 7 Declaraciones relativas a Protocolos anexos y 15 Declaraciones emitidas por diversos Estados miembros de las que la Conferencia ha tomado nota ${ }^{73}$.

El Tratado Lisboa reproduce el 95\% del fallido Proyecto de Constitución, pero suprime todos los símbolos constitucionales (bandera e himno), para reconducir el proceso constitucional a un proceso de reforma de los Tratados que enlaza directamente con el anterior de Niza y mantiene la estructura tradicional de textos y acuerdos separados, que ahora pasan a denominarse Tratado de la Unión Europea (TUE) y Tratado sobre el Funcionamiento de la Unión Europea (TFUE); asume por primera vez la denominación de Unión Europea a la que se atribuye personalidad jurídica y supera los textos del TCCE y del TCECA; sin embargo, no se incorpora formalmente la Carta de los Derechos Fundamentales

\footnotetext{
70 Reglas que, de acuerdo con lo dispuesto en el propio Tratado de Lisboa, van a mantener su aplicación en cuestiones sustanciales (como el cómputo de los votos del Consejo) hasta 2014.

71 Manuel BALLBÉ. «El Futuro del Derecho Administrativo en la Globalización: Entre la americanización y la Europeización», RAP, núm. 174, Vol. Especial «Homenaje al Profesor Ramón Parada Vázquez, septiembre-diciembre de 2007, Madrid, pág. 265: «mencionar las palabras constitución y federalismo en los sistemas multinivel es contraproducente, aunque sea nominal, los Estados se resisten a perder soberanía.» (E. MONNET).

72 La negociación ha sido inusitadamente acelerada - sin duda porque había un núcleo básico de materias consensuadas - y ha permitido concluirlo en cuatro meses y firmarlo dos meses después gracias a la exclusión los aspectos más polémicos y delicados del Tratado Constitucional y al establecimiento de cláusulas para exceptuar la aplicación del Tratado a aquellos Estados que más problemas podían tener en la ratificación (el Reino Unido y Polonia, sobre todo), de otra porque, salvo Irlanda, el procedimiento de ratificación va a ser parlamentario, excluyendo los riesgos que todo referéndum implica.

73 De este opaco bosque normativo no se va a proporcionar ninguna versión consolidada oficial durante el proceso de ratificación, seguramente para evitar facilitar su comparación con la Constitución Europea, por el temor de que resurjan dificultades políticas en algunos Estados miembros. Así pues, durante un tiempo serán inevitables los ejercicios de intertextualidad o el recurso a versiones no oficiales.
} 
que no aparece en el texto de los Tratados. Sólo indirectamente, gracias a la insistencia de los representantes del Parlamento Europeo manifestada en la Conferencia Intergubernamental, se prevé su carácter jurídico vinculante mediante la proclamación solemne por las tres instituciones políticas comunitarias - Parlamento Europeo, Consejo y Comisión-y su posterior publicación en el Diario Oficial de la Unión Europea ${ }^{74}$. Se abandona también el concepto de Ley Comunitaria y se arbitra una fórmula jurídica para que la Unión pueda adherirse al Convenio Europeo de Derechos Humanos, también mediante decisión unánime del Consejo, con la aprobación del Parlamento Europeo y de los Estados miembros. Lo que junto con la generalización del régimen de mayoría para la decisión de la práctica totalidad de los asuntos, y una nueva definición de los votos necesarios para mantener posiciones de bloqueo que entrará en vigor en 2014, y la consolidación de la figura del Presidente permanente del Consejo (2 años, más posible prórroga) permite afirmar que el nuevo Tratado facilitará un funcionamiento más ágil y efectivo de la Unión Europea y aporta avances significativos en el proceso de integración política, aunque se pierde la ocasión de consolidar unas instituciones comunes dotadas de verdadero poder político, que por el momento sigue en poder de los Estados, y así parece que seguirá mientras no se establezca el sistema de elección directa del ahora creado Presidente del Consejo, y se consoliden los poderes del Parlamento en materia de política internacional ${ }^{75}$.

Por el momento, el verdadero poder de la Unión reside en la fuerza expansiva de sus grandes principios (unidad de mercado y cláusulas de libre competencia y no discriminación) que unidos al elenco de sus competencias exclusivas que figuran en el Artículo 3 del Tratado de Funcionamiento: Unión aduanera, establecimiento de las normas sobre competencia necesarias para el funcionamiento del mercado interior, política monetaria de los Estados miembros cuya moneda es el euro, conservación de los recursos biológicos marinos, y la política comercial común, más las competencias sobre acuerdos internacionales, le otorgan una situación de preeminencia sobre las políticas de los Estados en el resto de las materias de competencia compartida: política económica y social, agricultura, medio ambiente, energía, transportes, redes, espacio de libertad y seguridad, mercado interior y salud pública, ejecución de sentencia y reconocimiento mutuo que se configuran como de competencia compartida en los artículos 5 y siguientes del Tratado. Sobre las que la Unión cuenta además con el instrumento

\footnotetext{
74 No aparece, por tanto, en el articulado de los tratados constitutivos, pero esa remisión le atribuye un rango jurídico similar al de estos. Conviene apuntar que los recelos hacia la Carta de algunos gobiernos como el inglés o el polaco provienen tanto de su posible utilización como base jurídica para incrementar la vis expansiva de las competencias comunitarias, cuanto de poder ser utilizados en materia de competencias privativas de los Estados. Por eso, el Tratado incorpora un Protocolo para acoger esas cautelas, que también se recogen en la propia Carta, al establecer que sus previsiones sólo se aplicarán a los Estados miembros cuando apliquen el Derecho de la Unión, y que no crean ni modifican las competencias de la Unión (art. 51).

75 Paz Andrés SÁENZ DE SANTAMARÍA. «El Tratado de Lisboa: comienza una nueva etapa para Europa», Diario La Ley, núm. 6851, 31 Dic. 2007, Año XXVIII, Ref. D-282, Editorial LA LEY 6903/2007
} 
de la supremacía de su Derecho para extender su presencia y su posición en cuando resulte necesario para conseguir los objetivos de los Tratados ${ }^{76}$.

\section{Codificación del concepto de servicios de interés económico general}

El concepto de servicio de interés económico general cuenta en los nuevos Tratados con una larga serie de declaraciones y reflexiones que consagran un nuevo reparto competencial en la materia, correspondiendo ahora a la Unión la competencia para concretar y definir las condiciones económico-financieras de las misiones de interés general y una paralización en la política de privatización del sector público europeo, especialmente el asistencial o no económico que queda fuera de los efectos del Tratado. Se consagra definitivamente el concepto servicio universal ${ }^{77}$, que no es más que otra técnica jurídica utilizada por el poder para mantener vivos los valores del servicio público: igualdad, la transparencia, la no discriminación, la continuidad, la accesibilidad, calidad, seguridad y precio razonable y asequible, sin renunciar a la introducción parcial y controlada de la libre competencia, pero ya sin tanta determinación y sin el alcance general que tuvo en los servicios de redes.

En los nuevos Tratados se reconocen expresamente las distintas categorías de servicios de interés general. Aparecen así con un contenido propio y distinto de los habituales servicios económicos de interés general, los servicios de inte-

76 Artículo 5.1. TUE: «La delimitación de las competencias de la Unión se rige por el principio de atribución. El ejercicio de las competencias de la Unión se rige por los principios de subsidiariedad y proporcionalidad.

2. En virtud del principio de atribución, la Unión actúa dentro de los límites de las competencias que le atribuyen los Estados miembros en los Tratados para lograr los objetivos que éstos determinan. Toda competencia no atribuida a la Unión en los Tratados corresponde a los Estados miembros.

3. En virtud del principio de subsidiariedad, en los ámbitos que no sean de su competencia exclusiva, la Unión intervendrá sólo en caso de que, y en la medida en que, los objetivos de la acción pretendida no puedan ser alcanzados de manera suficiente por los Estados miembros, ni a nivel central ni a nivel regional y local, sino que puedan alcanzarse mejor, debido a la dimensión o a los efectos de la acción pretendida, a escala de la Unión.

4. En virtud del principio de proporcionalidad, el contenido y la forma de la acción de la Unión no excederá de lo necesario para alcanzar los objetivos de los Tratados. Las instituciones de la Unión aplicarán el principio de proporcionalidad de conformidad con el Protocolo sobre la aplicación de los principios de subsidiariedad y proporcionalidad.»

77 Francisco SoSA WAGNER. «La actual encrucijada de los servicios y las empresas públicas locales», pág. 16 y 17. Revista de Estudios Locales, núm. extra, julio de 2007 (COSITAL) MADRID. «El poder público tiene que encargarse de que esos servicios se presten, Entonces entra en juego el mecanismo del llamado servicio universal que consiste en que, aun cuando se produce la liberalización del servicio, tal servicio universal ha de estar garantizado, en cualquier caso, a las personas más alejadas y con menos posibilidades económicas. En principio, de acuerdo con este modelo, las mismas empresas de gestión de los servicios financiarían esas pérdidas; la empresa que tiene la posición dominante se encargaría de la prestación de esos servicios, pero su coste estaría a cargo de las propias empresas del sector. Este es el modelo, aunque otra cosa es que funcione en la realidad». 
rés general no económicos, que no pueden resultar afectados por los $\operatorname{Tratados}^{78}$. Se acepta la posición y declaraciones del Parlamento Europeo (Resolución de 13 de enero de 2004) favorables a establecer un concepto específico de servicios de interés general en materias sociales y sanitarias, resistente a la privatización, y auspiciar un proceso de consultas, estudio y maduración que permita conocer con detalle la situación de los servicios sociales, sus niveles de calidad, su peso relativo en el PIB, y los distintos niveles de satisfacción declarados por los usuarios ${ }^{79}$. Se cierra a así la discusión abierta por las Comunicaciones de la Comisión y los Libros Blanco y Verde sobre los servicios no económicos que, por el momento, quedan excluidos de los Tratados y la Unión no tiene competencia sobre los mismos.

En cuanto a los servicios económicos de interés general, se reconoce la total discrecionalidad de los Estados (y de las autoridades regionales y locales) para prestar, hacer que se realicen y organizar servicios económicos de interés general, de acuerdo con el principio de subsidiariedad y eficacia. Declaración en la que hay que ver un apoyo expreso a favor de las políticas descentralizadoras a favor de los entes locales y a favor de la subsistencia de los monopolios locales, que se verán afectados por los futuros Reglamentos del Consejo o el Parlamento en materia de condiciones financieras de los servicios de interés general ${ }^{80}$.

\section{Protocolo sobre los servicios de interés general}

Artículo 1. «Los valores comunes de la Unión con respecto a los servicios de interés económico general con arreglo al artículo $14^{81}$ del Tratado de Funcionamiento de la Unión Europea incluyen en particular»:

- El papel esencial y la amplia capacidad de discreción de las autoridades nacionales, regionales y locales para prestar, hacer que se realicen y organizar los servicios de interés económico general lo más cercanos posible a las necesidades de los usuarios;

\footnotetext{
78 Los trascendentales sectores del agua y la energía siguen en manos de los Estados, salvo en materia de contratación armonizada, y serán objeto de nuevas directivas anticontaminación.

79 Ley 28/2006, de 18 de junio, de Agencias Estatales para la Mejora de los Servicios Públicos; Ley 11/2007, de 22 de junio, de Acceso Electrónico de los Ciudadanos a los Servicios Públicos.

80 Artículo 74. 3 del Anteproyecto de Ley Básica del Gobierno y la Administración Local: Se declara la reserva a favor de los municipios de las siguientes actividades o servicios esenciales: abastecimiento y depuración de aguas; recogida, tratamiento y aprovechamiento de residuos urbanos; transporte público urbano de viajeros; alumbrado público y pavimentación de vías públicas. La efectiva ejecución de estas actividades en régimen de monopolio requiere la aprobación provisional por el Pleno municipal y la definitiva por el órgano de gobierno de la Comunidad Autónoma.

81 Las altas partes contratantes, deseando enfatizar la importancia de los servicios de interés general, han convenido en las siguientes disposiciones interpretativas, que se incorporarán como anexo al Tratado de la Unión Europea y al Tratado de Funcionamiento de la Unión Europea.
} 
- la diversidad de los servicios de interés económico general y la disparidad de las necesidades y preferencias de los usuarios que pueden resultar de las diferentes situaciones geográficas, sociales y culturales;

- un alto nivel de calidad, seguridad y accesibilidad económica, la igualdad de trato y la promoción del acceso universal y de los derechos de los usuarios.

Artículo 2: «Las disposiciones de los Tratados no afectarán en modo alguno a la competencia de los Estados miembros para prestar, hacer que se realicen y organizar servicios de interés general que no sean económicos».

Este protocolo tiene el mismo valor que los propios Tratados, lo que significa el efectivo reconocimiento de los servicios de interés general como objetivo de la Unión ${ }^{82}$. La nueva regulación desarrolla y profundiza en las declaraciones y mandatos de los artículos 16 del Tratado de Niza y 36 de su Carta anexa. Desde el punto de vista de los ciudadanos, sus mandatos y declaraciones podrán alegarse como principios de Derecho comunitario, a la hora de recurrir las decisiones y los acuerdos de todos los poderes públicos en el establecimiento, modificación y ampliación de las distintas prestaciones de los servicios económicos de interés general, para demandar los principios de igualdad, calidad, y universalidad que, junto con la diversidad, gozan ahora de la primacía del Derecho comunitario originario sobre el Derecho nacional ${ }^{83}$.

Con todo, la novedad más importante del Tratado de Lisboa aparece en el artículo 2 del Protocolo de los Servicios de Interés General, que excluye del ámbito competencial de la Unión la prestación de los servicios de interés general que no sean económicos. La referencia a prestar, hacer que se realicen u organizar, autoriza todas las posibilidades. Desde la gestión directa (prestar) hasta la regulación del servicio universal (hacer que se realicen), pasando por todo tipo de fórmulas intermedias de gestión indirecta y de gestión compartida, según la planificación y la organización que se establezca por cada Estado. No obstante, hay que recordar

82 El Protocolo sobre los servicios de interés general aparece con el ordinal 6, justo tras los protocolos sobre los grandes y tradicionales principios de la Unión Europea:

1. Protocolo sobre el cometido de los Parlamentos nacionales en la Unión Europea

2. Protocolo sobre la aplicación de los principios de subsidiariedad y proporcionalidad

3. Protocolo sobre el mercado interior y la competencia

4. Protocolo sobre la aplicación de la Carta de Derechos Fundamentales a Polonia y al Reino Unido

5. Protocolo sobre el ejercicio de las competencias compartidas

Lo que evidencia la elevación de rango de los servicios de interés general en el nuevo TUE.

83 SSTJCE de 28 de junio de 1978 Simmenthal (70/77, Rec. P. 1.453). TJCE de 27 de marzo de 1963, as. Da Costa - 28 a30/62, Rec. P. 75; y Cilfit, de 6 de octubrede1982. El juez nacional puede hacer un juicio positivo de validez, pero nunca lo puede hacer negativo, STJE, asunto Foto-Frost. Será la Jurisprudencia del TJCE, como es habitual, la encargada de conceder a los derechos de la Carta la primacía del Derecho comunitario. 
las obligaciones que asumen todos los Estados en el TUE para hacer efectivos un mercado interior y el mayor valor de las reglas de la competencia, aunque se trate de una aplicación del principio de subsidiariedad, y de los principios de lealtad y cooperación; no obstante, se rechaza la propuesta del Libro Blanco sobre la necesidad «establecer un marco claro y transparente para la selección de las empresas encargadas de prestar un servicio de interés general», que debe compartir cartel con las fórmulas de la regulación, y con la prestación por medio propio.

\section{Principio de subsidiariedad y cláusula de preferencia local}

El Protocolo asume las propuestas del Libro Blanco en materia de subsidiariedad; reforzando así las grandes declaraciones y principios de la Carta europea de la Autonomía Local, con una interpretación favorable a la aplicación del principio de subsidiariedad a favor de los entes locales que, por primera vez, obtienen una mención competencial a su favor en el Derecho originario ${ }^{84} \mathrm{Se}$ garantiza la participación de las Entidades Locales en la gestión de los servicios públicos con carácter general, tal como establece el artículo 3 de la Carta Europea de la Autonomía Local, de 15 de octubre de $1985^{85}$.

La mención directa al principio de subsidiariedad en la prestación de los servicios económicos de interés general implica establecer una regla de preferencia local. El nuevo proyecto de Ley Básica del Gobierno Local ${ }^{86}$, y las disposiciones de los nuevos Estatutos de Autonomía ya aprobados tienen así un nuevo instrumento para atribuir la prestación de nuevos servicios a la Administración Local, y propulsar una mayor participación local en la prestación de los servicios del Estado y de las Comunidades Autónomas. Desde este punto de vista, supone también un apoyo legal expreso a favor de las nuevas propuestas doctrinales para conceder en España un mayor ámbito a la teoría de la garantía institucional de la Administración Local con un contenido más

84 Francisco VELASCO CABALLERO. «Subsidiariedad y Competencia en la Reforma de los Entes Loca-
les». Revista de Estudios Locales, pág. 53, COSITAL núm. Especial, julio 2005, MADRID. El principio
de subsidiariedad, en su doble vertiente de proximidad y de eficacia, así como los criterios de flexibili-
dad en la atribución de las competencias municipales, se postulan como rectores de todo el sistema de
atribución de competencias a los entes locales en el Libro Blanco. Deben formar parte del concepto de
bases del Régimen Local y tener, en consecuencia, general aplicación, de tal manera que, como princi-
pio político jurídico básico, resulte exigible de la legislación sectorial de las CCAA, recuperando el
carácter de canon de constitucionalidad, más allá de ese mínimo que asegura la garantía institucional ex
artículo $137 \mathrm{CE}$

85 Art. $3 .^{\circ}$ Concepto de la autonomía local: 1 . Por autonomía local se entiende el derecho y la capacidad efectiva de las Entidades locales de ordenar y gestionar una parte importante de los asuntos públicos, en el marco de la Ley, bajo su propia responsabilidad y en beneficio de sus habitantes.

4. Las competencias encomendadas a las Entidades locales, deben ser normalmente plenas y completas. No pueden ser puestas en tela de juicio ni limitadas por otra autoridad central o regional, más que dentro del ámbito de la Ley.

86 De sustitución del fallido anteproyecto de Ley Básica del Gobierno y la Administración, de 03-05-06. 
extenso del interés local que la mera pervivencia o continuidad de los entes locales ${ }^{87}$.

\section{Tratado de Funcionamiento}

El Artículo 14 del Tratado de Funcionamiento de la Unión reitera los contenidos del Tratado de Niza sobre los servicios de interés general, pero atribuye ahora una competencia directa al Parlamento y al Consejo de la UE para determinar los principios y condiciones económicas y financieras que les permitan cumplir sus cometidos. Aquellas «misiones a ellos encomendados» que figuraban en el artículo 86.2 del TCEE pasan a ser principios económicos financieros y condiciones a establecer por el Parlamento y por el Consejo Europeo por el procedimiento legislativo ordinario, a propuesta de la Comisión. La definición de las condiciones económico-financieras de los servicios de interés general es materia de plena competencia exclusiva de la Unión, y además protegida por el procedimiento legislativo ordinario. Sólo podrán desarrollarse por Reglamentos del Consejo o del Parlamento:

«Sin perjuicio del artículo 4 del Tratado de la Unión Europea ${ }^{88}$ y los artículos 93, 106 y 107 del presente Tratado, y a la vista del lugar que los servicios de interés eco-

87 A. FANLO LORAS, Fundamentos constitucionales de la autonomía local. El control sobre las corporaciones locales; el funcionamiento del modelo constitucional de autonomía local, CEC, Madrid, 1990; E. MARTín Mateo y F. SosA WAGNER. «Cincuenta años en la Administración local», RAP, núm. 150, 1999; L. PAREJO ALFONSO. «El régimen jurídico de la Administración local hoy, en El sistema político local: nuevo escenario de gobierno» (C. AlBA y E. VANACLOCHA), ROE, Madrid, 1997; J. L. CARRo FERnÁNDEZVALMAYOR. «El debate sobre la autonomía municipal», núm. 147 RAP, 1998, págs. 61 y ss; E. SÁNCHEZ GOYANES. La potestad normativa del municipio español. Ordenanzas, reglamentos, planes urbanísticos, normas, El Consultor, Madrid, 2000; J. GARCíA MORRILLO. «La configuración constitucional de la autonomía local, Madrid, 1996; Tomás FONT I LLOVET. «La renovación del poder local: Avances en la configuración jurídica e institucional del gobierno local», Cuadernos de Derecho Local, y L. ORTEGA. «La potestad normativa local», págs. 39-55, en Anuario del Gobierno Local 2001, Madrid; E. AJA. «Configuración constitucional de la autonomía local», en Informe sobre el gobierno local (Tomás FONT, dir.), MAP y Fundación Pi i Sunyer, Madrid, 1992; J. GARCíA RocA. «El concepto actual de autonomía local según el bloque de la constitucionalidad», REALA, Núm. 282, 2000. Casimiro LóPEZ. «Nuevo sistema de atribución y defensa competencial de los EELL», Cuadernos de Derecho Local, n .15, octubre de 2007 (Fundación Democracia y Gobierno Local).

88 Artículo 4 1. De conformidad con lo dispuesto en el artículo 5 toda competencia no atribuida a la Unión en los Tratados corresponde a los Estados miembros.

2. La Unión respetará la igualdad de los Estados miembros ante los Tratados así como su identidad nacional, inherente a las estructuras fundamentales políticas y constitucionales de éstos, también en lo referente a la autonomía local y regional. Respetará las funciones esenciales del Estado, especialmente las que tienen por objeto garantizar su integridad territorial, mantener el orden público y salvaguardar la seguridad nacional. En particular, la seguridad nacional seguirá siendo responsabilidad exclusiva de cada Estado miembro.

3. Conforme al principio de cooperación leal, la Unión y los Estados miembros se respetarán y asistirán mutuamente en el cumplimiento de las misiones derivadas de los Tratados. Los Estados miembros adoptarán todas las medidas generales o particulares apropiadas para asegurar el cumplimiento de las obligaciones derivadas de los Tratados o resultantes de los actos de las instituciones de la Unión. 
SERVICIOS DE INTERÉS GENERAL Y PRINCIPIO DE COMPETENCIA: DEL TRATADO CEE...

nómico general ocupan entre los valores comunes de la Unión, así como de su papel en la promoción de la cohesión social y territorial, la Unión y los Estados miembros, con arreglo a sus competencias respectivas y en el ámbito de aplicación de los Tratados, velarán por que dichos servicios actúen con arreglo a principios y condiciones, en particular, económicas y financieras, que les permitan cumplir su cometido. El Parlamento Europeo y el Consejo establecerán dichos principios y condiciones mediante reglamentos con arreglo al procedimiento legislativo ordinario ${ }^{89}$, sin perjuicio de la competencia que incumbe a los Estados miembros, dentro del respeto a los Tratados, para prestar, encargar y financiar dichos servicios» ${ }^{90}$.

La nueva regulación de los servicios de interés económico general mantiene la iniciativa estatal para establecer, prestar y regular todo tipo de servicios de interés general, pero atribuye a la Unión competencia para definir los principios y las condiciones de las misiones de servicio público. El artículo 14 reproduce lo dispuesto en el Proyecto de Constitución «Sin perjuicio de los artículos III-55, III-56 y III-136, y a la vista del lugar que los servicios de interés económico general ocupan, como servicios a los que en la Unión todos conceden valor, así como de su papel en la promoción de la cohesión social y territorial de ésta, la Unión y sus Estados miembros, con arreglo a sus competencias respectivas y en el ámbito de aplicación de la Constitución, velarán por que dichos servicios actúen con arreglo a principios y condiciones, económicos y financieros en particular, que les permitan cumplir su cometido. Dichos principios y condiciones se definirán mediante leyes europeas», con la obligada supresión de la referencia a la Ley comunitaria que, para enfatizar la similitud, refiere ahora el TFUE, al procedimiento legislativo ordinario, asumiendo así la posición del Libro Verde favorable a otorgar un mayor papel a la Unión en la definición de la financiación de los servicios de interés económico general, y señalar las excepciones totales o parciales a la libre competencia en los ámbitos territoriales, las materias competenciales y los sectores económicos que, por su mayor o menor trascendencia en relación con los intercambios comerciales y con los movimientos de capital, admitan una presencia mayor de la libre competencia o, alternativamente, puedan excluirla como sucede con los servicios locales monopolizados.

La Comisión podrá utilizar la información que tienen que suministrar los Estados por imperativo de la nueva Directiva sobre Transparencia, que se convierte así en una herramienta imprescindible para facilitar la formulación de las propuestas de Decisión o Directiva que se presenten para armonizar las políticas estatales.

89 La exclusión de la regla de la unanimidad facilitará la aprobación de unas condiciones de general aplicación en todos los Estados. Lo que sin lugar a dudas corregirá la tendencia a la dispersión y al casuismo que está implícita en la libre y discrecional iniciativa estatal para prestarlos (gestión directa o indirecta) o para reglamentarlos con la técnica del servicio universal.

90 Evidentemente, la vigilancia sobre el cumplimiento de los principios de Derecho comunitario y la vigilancia sobre el cumplimiento de los Reglamentos que se aprueben por el Consejo o el Parlamento en los servicios de interés económico general corresponde a la Comisión. 


\section{Transportes y ayudas públicas}

\section{Artículo 93}

El Artículo 93 del Tratado reitera la única referencia que figuraba en el TCEE a los servicios públicos en materia ayudas a las necesidades de los transportes, que ahora se extienden a otras obligaciones de servicio público, en clara referencia al concepto de servicio universal. Teniendo en cuenta que las condiciones económico-financieras de los servicios de interés general son competencia exclusiva de la Unión. Se declaran compatibles las ayudas en materia de coordinación o por el reembolso de las obligaciones de servicios público, que ahora corresponde definir a la normativa comunitaria para todo tipo de servicios de interés general.

\section{Artículos 101 a 109}

Los artículos 101 a 103 reiteran sin novedad la regulación de los articulo 81 a 89 vigente desde las versiones consolidadas del Tratado de Amsterdam. Se detalla la aplicación efectiva de los principios estructurales de libre competencia y prohibición de concesión de ayudas públicas, y el objetivo del mercado único. El régimen de ayudas públicas queda prohibido salvo las excepciones que figuran en los artículos 106 a 108 del propio Tratado y sometido a la vigilancia, control y autorización previa a cargo de la Comisión, de acuerdo con los Reglamentos aprobados al efecto por el Consejo. Se repite la fórmula vigente en el artículo 86.2 del TCEE, que ahora hay que relacionar con lo dispuesto en el artículo 14 del mismo Tratado, dado que son el Parlamento y el Consejo europeos los competentes para definir las condiciones económicos financieras que justifiquen las excepciones y su verdadero alcance ${ }^{91}$. La nueva redacción es un acarreo de materiales que reitera lo dispuesto en las anteriores versiones de los Tratados. La novedad está ahora en el comentado artículo 14 que atribuye a la Unión competencia legislativa en la materia, y en la Directiva 111/2006.

El artículo 107 mantiene el régimen de compatibilidades en materia de ayudas estatales vigente desde el Tratado de Amsterdam. Se parte de una cláusula general de prohibición por incompatibilidad para establecer un régimen de

91 Artículo 106. 1 TFUE. «Los Estados miembros no adoptarán ni mantendrán, respecto de las empresas públicas y aquellas empresas a las que concedan derechos especiales o exclusivos, ninguna medida contraria a las normas de los Tratados, especialmente las previstas en los artículos 12 y 101 a 109 del presente Tratado, ambos inclusive.

2. Las empresas encargadas de la gestión de servicios de interés económico general o que tengan el carácter de monopolio fiscal quedarán sometidas a las normas de los Tratados, en especial a las normas sobre competencia, en la medida en que la aplicación de dichas normas no impida, de hecho o de derecho, el cumplimiento de la misión específica a ellas confiada. El desarrollo de los intercambios no deberá quedar afectado en forma tal que sea contraria al interés de la Unión». 
compatibilidad: Ayudas de carácter social, concedidas a los consumidores finales; ayudas en caso de calamidad pública y, temporalmente, las ayudas a la unificación alemana.

Se establece un régimen de autorización previa para las ayudas destinadas a favorecer el desarrollo económico de regiones en las que el nivel de vida sea anormalmente bajo o en las que exista una grave situación de subempleo. Para fomentar la realización de un proyecto importante de interés común europeo o las destinadas a poner remedio a una grave perturbación en la economía de un Estado miembro. Las destinadas a facilitar el desarrollo de determinadas actividades o de determinadas regiones económicas, siempre que no alteren las condiciones de los intercambios en forma contraria al interés común. Y las ayudas destinadas a promover la cultura y la conservación del patrimonio, cuando no alteren las condiciones de los intercambios y de la competencia en la Unión en contra del interés común. Las demás categorías de ayudas que determine el Consejo por decisión a propuesta de la Comisión.

\section{Declaraciones relativas a las disposiciones de los tratados}

La complejidad de los nuevos Tratados se confirma con su nutrida serie de declaraciones anexas, a las que hay que unir las declaraciones de diversos Estados. La primera declaración anexa al Tratado asume la vigencia de la Carta de los Derechos Fundamentales de la Unión para reconocer su carácter jurídicamente vinculante, que confirma los derechos fundamentales garantizados por el Convenio Europeo para la Protección de los Derechos Humanos y de las Libertades Fundamentales y tal como resultan de las tradiciones constitucionales comunes a los Estados miembros. En realidad, se trata de una cláusula de delimitación competencial entre la Unión y los Estados: «La Carta de los Derechos Fundamentales de la Unión Europea, que tiene carácter jurídicamente vinculante confirma los derechos fundamentales garantizados por el Convenio Europeo para la Protección de los Derechos Humanos y de las Libertades Fundamentales y tal como resultan de las tradiciones constitucionales comunes a los Estados miembros. La Carta no amplía el ámbito de aplicación del Derecho de la Unión más allá de las competencias de la Unión ni crea ninguna nueva competencia ni ningún nuevo cometido para la Unión y no modifica las competencias y cometidos definidos por los Tratados».

Es evidente que el mandato cerrado del Consejo para alcanzar un nuevo Tratado incluía una prevención expresa sobre el «valor» de la Carta con la firme intención de evitar la «vis» expansiva que tienen las cartas de derechos, en cuanto instrumentos al servicio de los tribunales para la interpretación y la aplicación del derecho. Lo que explica la referencia explícita a que los derechos reconocidos por la Carta no modifican el trascendental reparto competencial que ahora figura en los artículos 4, 5, 6 y 7 del Tratado de Funcionamiento entre los Estados y la Unión, que distingue entre competencias exclusivas, comparti- 
das, y facultades o poderes de coordinación en materia de política económica, energética y de empleo. Sin embargo, es dudoso que lo hayan logrado; por el contrario, el expreso reconocimiento de una larga lista de materias susceptibles de competencias compartidas y el reconocimiento de facultades y poderes de coordinación a favor de la Unión en materias de política económica, de empleo, social, y de energía extienden notablemente el ámbito del Derecho comunitario y, de resultas, amplían las posibilidades de aplicación de los derechos reconocidos en la Carta en todo tipo de asuntos en los que pueda resultar de aplicación una norma comunitaria ${ }^{92}$.

El Tratado de Lisboa incorpora la mayoría de las novedades y propuestas que figuraban en el Proyecto de Constitución europea superando las dudas y vacilaciones sobre el alcance de los servicios de interés general. De acuerdo con las propuestas que figuran en el Libro Blanco, los servicios de interés general adquieren en el Tratado de Lisboa la relevancia que merecen como principio común a todos los Estados. La dedicación de un nuevo Protocolo destinado exclusivamente a regular los servicios de interés económico general, con exclusión de los no económicos es la mayor novedad que se completa con la atribución a la Unión de la competencia para regular los requisitos y las condiciones económicos financieras de los servicios de interés general que figura en el artículo 14 del Tratado de Funcionamiento. Tarea que se verá facilitada por el alcance general de la obligación de suministro de información que establece la nueva Directiva 111/2006, sobre Transparencia financiera.

En definitiva, los servicios de interés general pasan de las grandes declaraciones formales que figuran en la Carta y en el Tratado de Amsterdam a constituirse en uno de los valores fundamentales de la Unión, con el mismo nivel que el resto de los principios estructurales. Lo que obliga a distinguir entre servicios de interés general económicos y no económicos que quedan extra muros del Tratado y son de libre competencia estatal, que se ejercerá con respeto al resto de los principios del Tratado, y a definir lo que hay que entender por servicio económico de interés general y por obligaciones de servicio universal, que pasan a tener el rango de Derecho originario. Correspondiendo a la Unión establecer los principios y las condiciones económico financieras que les permitan cumplir su cometido, lo que permitirá establecer categorías y clases y un tratamiento homogéneo en todos los Estados miembros. En cuanto a la doctrina del medio propio, hay que entenderla asumida por la discrecionalidad que confiere a los Estados el artículo 1 del Protocolo de los servicios públicos para prestar directamente servicios de interés general.

92 Su vigencia se confirma con la Declaración de exclusión de la Carta que formulan el Reino Unido y Polonia aclaran su obligatoriedad. 